\title{
LOS LIBROS DE NICANOR PARRA
}

\section{César Soto}

Este estudio bibliográfico de la obra de Nicanor Parra trata de pesquisar el origen de las primeras publicaciones de cada uno de los libros, poemas sueltos y publicaciones de todo orden del poeta. El resultado es, también, un asomo al contexto en que cada obra fue publicada.

This bibliographic study of Nicanor Parra's work endeavors to determine the origin of the first editions of each of the books, individual poems and writings of all sorts by the poet. The result also provides a glimpse of the context in which each work was published.

presente estudio bibliográfico de las obras de Nicanor Parra está basado en las primeras ediciones en castellano. Hay que considerar que algunos poemas y antipoemas fueron publicados por primera vez en Estados Unidos. El célebre texto "Los profesores", por ejemplo, se editó por primera vez en castellano en Nueva York y sólo un cuarto de siglo más tarde fue incorporado a una de sus obras en Chile: Hojas

CÉSAR Soto Gómez (Iloca, 1951). Poeta. Estudió filosofía en el Instituto Pedagógico de la Universidad de Chile. Fundó el Estudio Bibliográfico América del Sur. Es autor de Consumatum est!, Antipoemas del país de las medias aguas, Nihil novum sub sole y Retratos hablados del siglo XX y otros poemas. Es miembro de la Sociedad de Bibliófilos de Chile y de la Sociedad Chilena de Historia y Geografía. Email: csotogomez@gmail.com

El autor agradece a los poetas Miguel Naranjo, Adán Méndez, Cristóbal Joannon, Gloria Dunkler, Kurt Folch y Guillermo García. Asimismo, a los historiadores Víctor Manuel Avilés y Juan Guillermo Prado por sus valiosas colaboraciones y aportes en el presente trabajo. 
de Parra. Existen otros textos publicados en editoriales efímeras, revistas y en hojas volantes de las cuales fue difícil encontrar registros. Es el caso de "Mil novecientos treinta" y otros que con el paso de los años fueron incorporados a antologías editadas en Madrid, Santiago de Chile, México o Buenos Aires. Hemos consultado a diversos bibliófilos, poetas e historiadores y pedimos excusas si se hubiese deslizado algún error en las descripciones o la omisión de algún opúsculo.

\section{REVISTA NUEVA y AURORA DE CHILE}

En la Revista Nueva, del Internado Barros Arana, correspondiente al año 1935, aparece la primera publicación de un poema de Nicanor Parra: "Sensaciones" y un texto narrativo (que podría llamarse un anticuento): "Gato en el camino".

El gesto literario que anunciaba "Gato en el camino" iba a prolongarse, en efecto, en el segundo y último número de Revista Nueva, en 1936, en el que aparecería "El ángel (tragedia novelada)". "Un revoltijo padre de cosas, un desorden, pero de vez en cuando con relámpagos" - cuenta Nicanor Parra sobre estos textos-. "En ese tiempo, me parece, había leído a Pirandello, concurría a algunos espectáculos, veía películas de la época. De manera que el espíritu de la cultura moderna de algún modo llegaba a mí". 1

En la revista Aurora de Chile, de la Alianza de Intelectuales para la Defensa de la Cultura, fundada por Pablo Neruda y cuyo primer número fue publicado en 1938, Parra da a conocer, en el n. ${ }^{\circ} 11$ (junio de 1939), el cuento "Tomás o el ayudante del otoño", además de una breve nota sobre la recitadora y actriz Inés Moreno: "Aspectos de Inés Moreno". En el n. ${ }^{\circ} 16$ (noviembre de 1939), publica el poema "Ultramar".

CANCIONERO SIN NOMBRE. Santiago de Chile: Nascimento, 1937.

Hemos conocido comentarios de esta obra del mismo autor, llamándolo "un pe(s)cado de juventud" o "este libro que no debiera existir". Recibió el Premio Municipal de Literatura. Según Parra, "en la época en que escribí Cancionero sin nombre yo estaba recién en los elementos del surrealismo. Tenía una formación garcialorquiana y lo más

${ }^{1}$ Leonidas Morales, Conversaciones con Nicanor Parra (Santiago: Andrés Bello, 1972). 


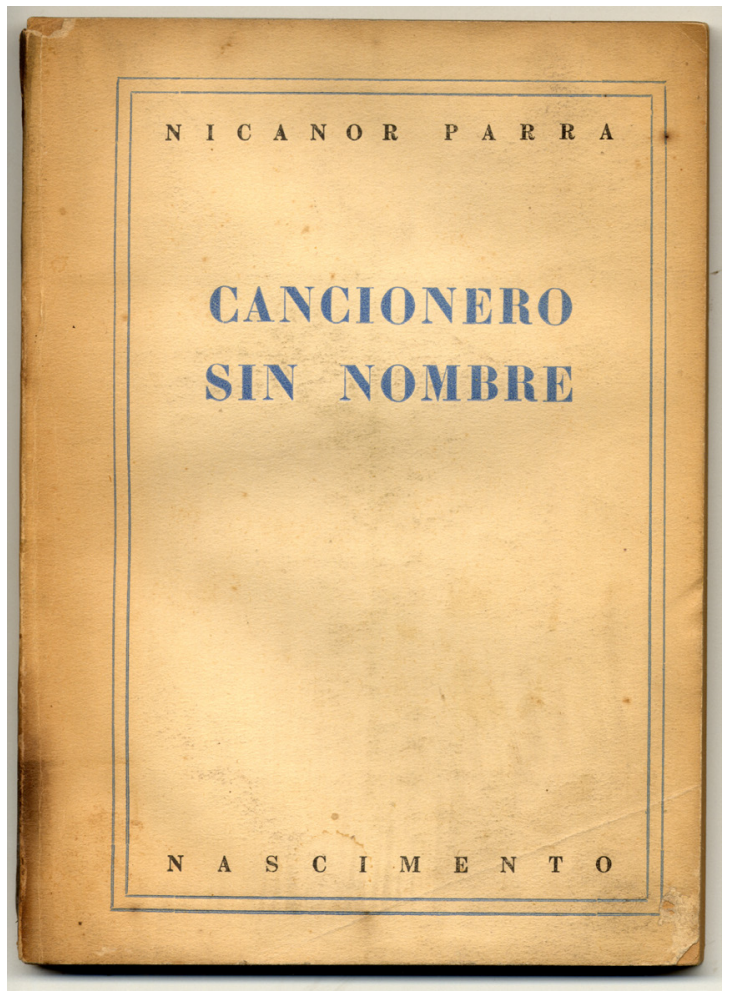

Cancionero sin nombre, 1937. Primer libro de Nicanor Parra.

que pude hacer fue introducir una que otra imagen surrealista. Bueno, había ya surrealismo en el propio García Lorca". ${ }^{2}$

Este libro está dedicado a siete de sus compañeros de generación: Omar Cerda, Carlos Pedraza, Jorge Millas, Jorge Cáceres, Victoriano Vicario, Luis Oyarzún y Carlos Guzmán.

8 NUEVOS POETAS CHILENOS. Suplemento de la Revista de la Sociedad de Escritores de Chile, Universidad de Chile, 1939.

El antologador y presentador de este trabajo es Tomás Lago. Los ocho poetas incluidos son: Luis Oyarzún, Jorge Millas, Nicanor Parra, Alberto Baeza Flores, Omar Cerda, Victoriano Vicario, Óscar Castro y Hernán Cañas, todos ellos nacidos entre 1910 y 1917.

Entre los seleccionados, el que cuenta con mayor representación es Parra (14 poemas), cuyo ascendiente sobre sus compañeros puede

\section{Ibídem.}




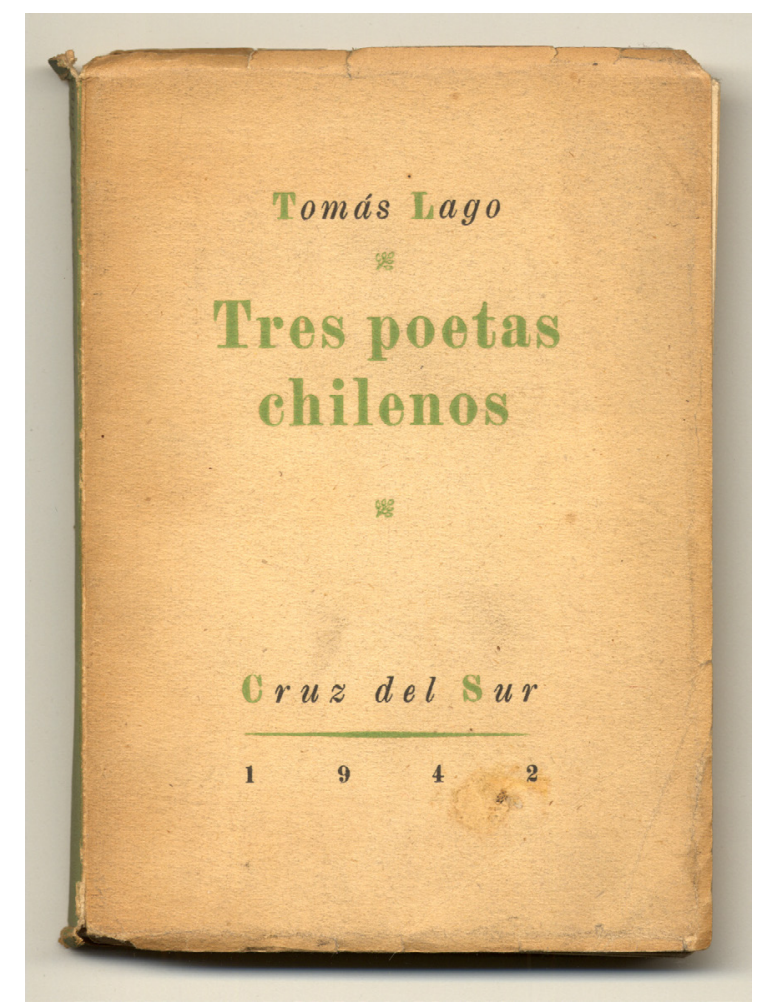

Tres poetas chilenos, 1942. Antología de Tomás Lago, que incluyó a Victoriano Vicario, Óscar Castro y Nicanor Parra.

constatarse, por otra parte, en el hecho de que dos de los poemas de Millas ("Palabras a Nicanor Parra" y "Nicanor el Simbad") lo aluden explícitamente. En una breve nota biográfica, se dice que Parra "tiene por publicar un libro de sonetos, Simbad el marino, y prepara Dos años de melancolía". La publicación de ambos libros no llegó a concretarse. Sólo un soneto de la obra Simbad el marino ha sido antologado en innumerables ocasiones: "La mano de un joven muerto", en el cual hace referencia a sus visiones del terremoto de Chillán el año 1939.

TRES POETAS CHILENOS. Antología de Tomás Lago. Santiago de Chile: Cruz del Sur, 1942.

Antología seleccionada, anotada y prologada por Tomás Lago. El volumen pertenece a la colección Autores Chilenos, que dirigía Manuel Rojas. Los "tres poetas chilenos" son Nicanor Parra, Victoriano Vicario y Óscar Castro. 


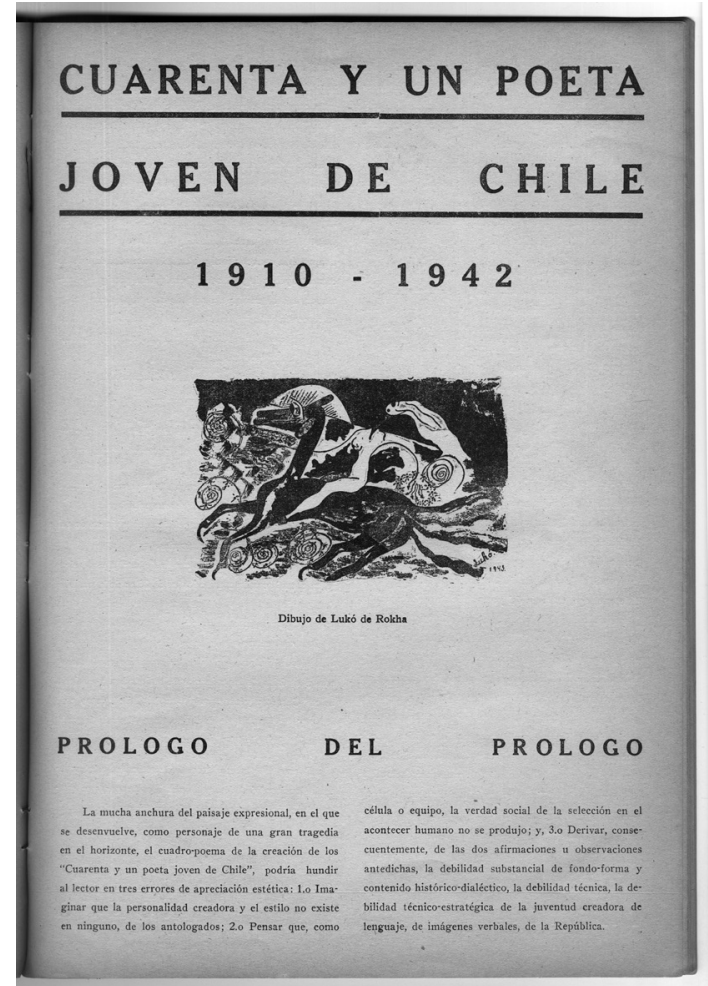

Cuarenta y un poeta joven de Chile. Antología de Pablo de Rokha, en revista Multitud n. $40,1942$.

CUARENTA Y UN POETA JOVEN DE CHILE. Antología de Pablo de Rokha. En la revista Multitud, n. ${ }^{\circ}$ 40, año Iv, 1942.

"Himno guerrero" es el título del poema de Nicanor Parra antologado por Pablo de Rokha.

13 POETAS CHILENOS (1938-1948). Antología de Hugo Zambelli. Valparaíso: imprenta Roma, 1948.

Selección y prólogo del poeta Hugo Zambelli. Aunque esta antología - "no muy clarividente pero tampoco ciega", a decir del poeta Enrique Lihn ${ }^{3}$ - no tenga la ambición ni la significación histórica de las dos mencionadas antologías de Tomás Lago, es importante en la trayec-

${ }^{3}$ Citado en Nicanor Parra, Obras completas \& algo + / Vol. I (Barcelona: Galaxia Gutenberg - Círculo de Lectores, 2006), 1022. 
toria de Parra por ser la primera en recoger algunos de los antipoemas — "La trampa", "Los vicios del mundo moderno" y "La víbora"- que serán luego incorporados, sin variantes, a la tercera parte de Poemas y antipoemas.

\section{“CARTA A TOMÁS LAGO”, OXFORD, 1949.}

En la investigación de la evolución del lenguaje que conocemos de los poemas y antipoemas, existe una importante carta dirigida por Nicanor Parra a Tomás Lago. Se produce en la próximas páginas en forma íntegra.

\section{EL QUEBRANTAHUESOS.}

Bajo este título, Nicanor Parra y un grupo de jóvenes poetas y creadores, que se encontraban frecuentemente en su departamento de la calle Mac-Iver n. ${ }^{\circ} 22$, expusieron periódicamente durante varias semanas sucesivas del año 1952, en dos puntos céntricos de Santiago (el restaurante El Naturista, de calle Ahumada y en calle Bandera, frente a los Tribunales de Justicia), unos collages satíricos hechos de recortes de diarios. Entre quienes realizaron los Quebrantahuesos estaban, además de Parra, Jorge Berri (mecánico), Roberto Humeres (esteta), Alejandro Jodorowsky (poeta, mimo), Enrique Lihn (poeta), Luis Oyarzún (humanista) y Jorge Sanhueza (bibliófilo).

Hay que hacer notar que en su infancia Nicanor Parra y su familia vivieron en Santiago, en una pieza en la calle San Pablo con Manuel Rodríguez. "Segundos pisos y pasillos oscuros, largos y altos", cuenta el poeta en sus conversaciones con Leonidas Morales. ${ }^{4}$ Otro recuerdo se refiere a los muros, "que estaban empapelados con papeles de diario. Yo empecé a aprender a leer en estos papeles de diario. Eran especies de 'quebrantahuesos', porque un diario estaba pegado encima de otro y se juntaba una frase con otra". 5

Nueve de estos ejemplares fueron publicados con posterioridad en la revista Manuscritos, del Departamento de Estudios Humanísticos de la Universidad de Chile, el año 1975, con prólogo del poeta Ronald Kay, quien fue el descubridor de estas obras olvidadas en el tiempo.

\footnotetext{
${ }^{4}$ Morales, Conversaciones.

5 Ibídem.
} 


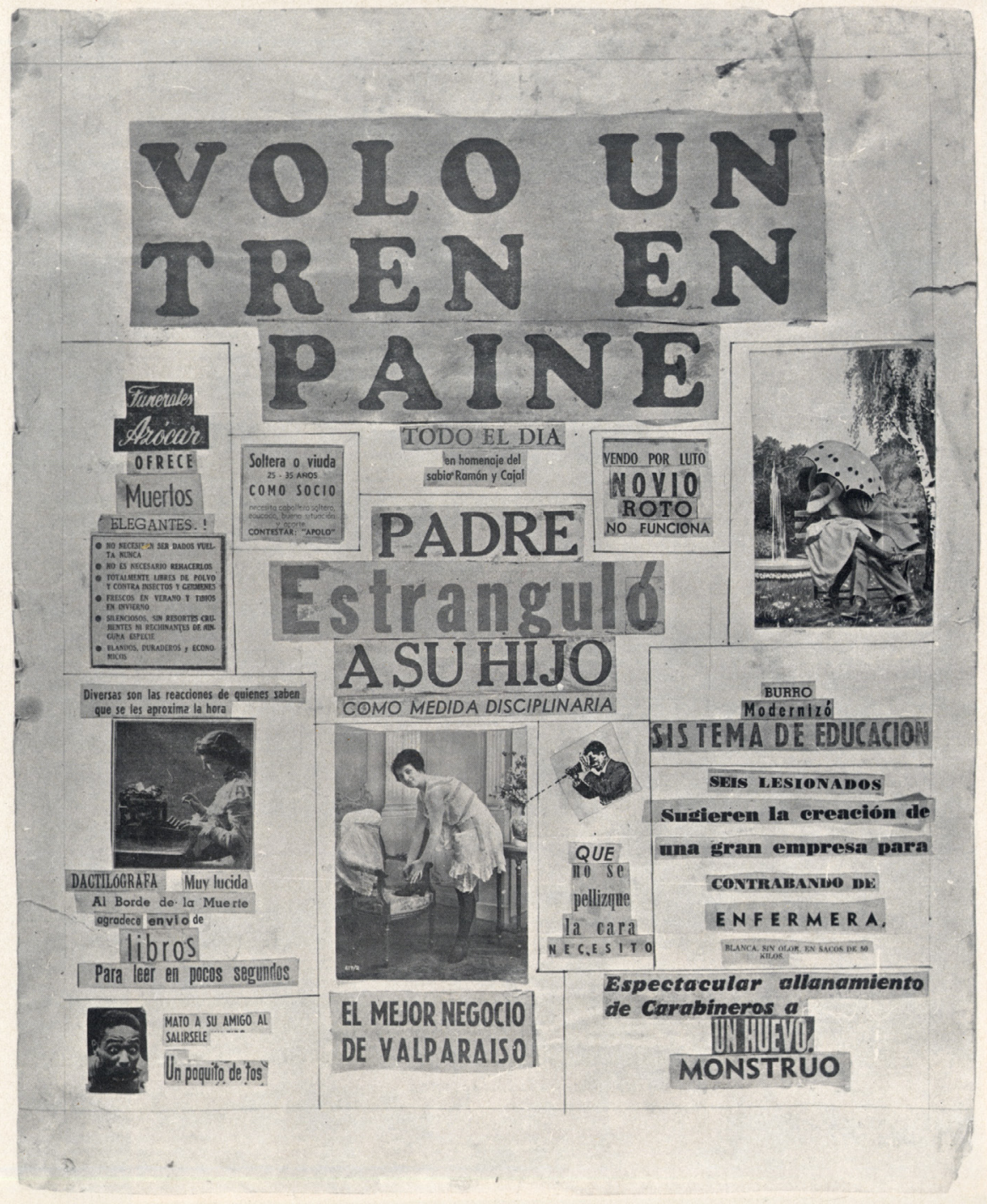

Un ejemplar del Quebrantahuesos, 1952. 


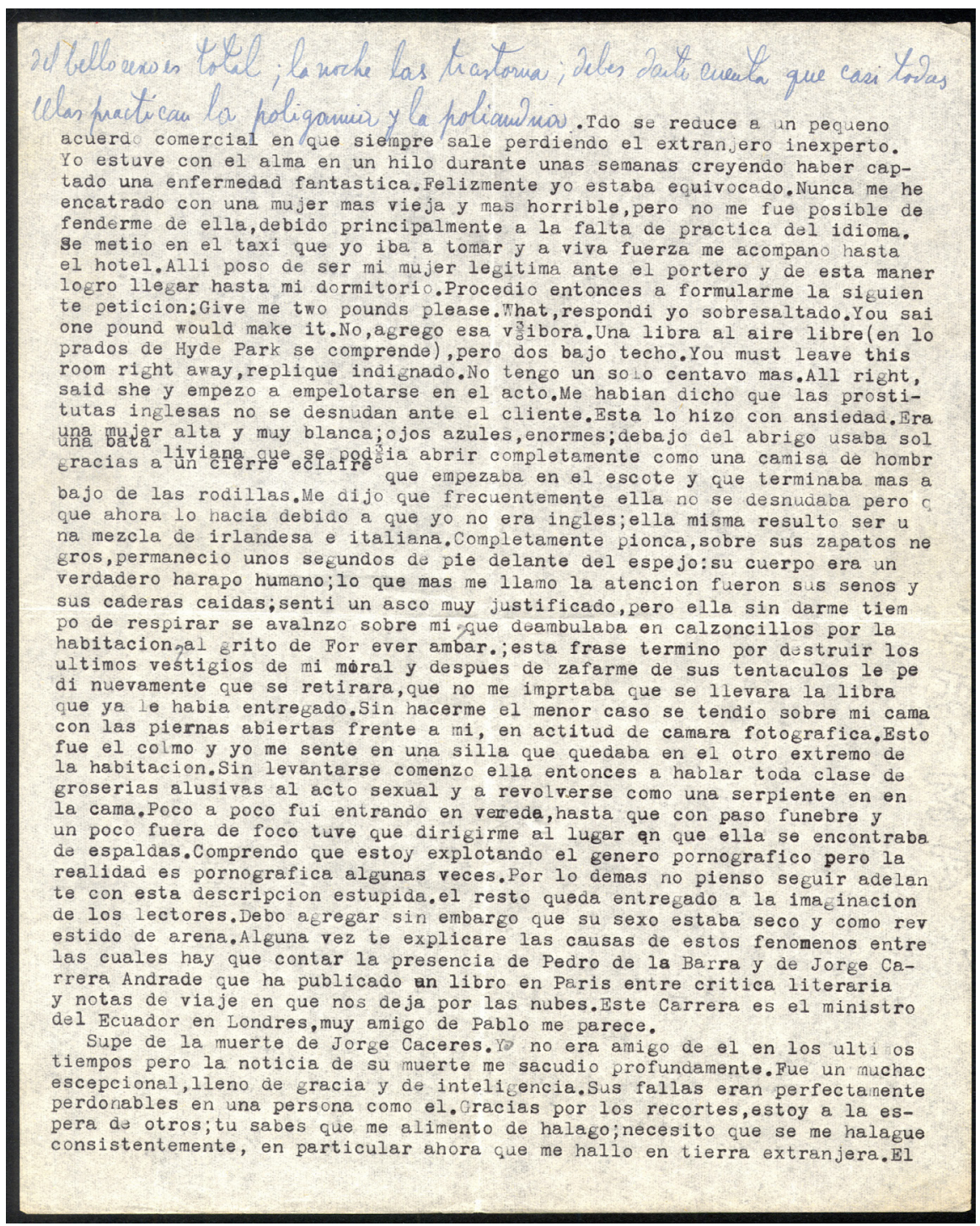

"Carta a Tomás Lago", Oxford, 1949. 
chico Oyarzun acaba de regresar a Londres;1lego el Sabado, hoy es Lunes, mien tra yo te escribia esta carta. der conel objeto de dedicarme a festejarlo. XKKX Se ve algo envejecido y cor pulento, dentro de ciertos limites. Estuyimos a punto de disgistarnos ayer tarde por cuestiones politicas; declaro que encsao de refriega entre Rusia. y occidente el se alistaria al lado aximax de las democracias. No se $p$ porque llegamos a tocar este punto.doloroso. En general nuestra entrevista. fue un exito.El Chico se ha adherido a mis nuevas convicciones esteticas. Si hay que darle algun credito a sus palabras es necesario mirar a mis ulti mas poesias como hacia una ciencia literaria nueva. El chico tiene toda la razon. No pienas tu $10 \mathrm{mismo}$. Por favor Tomas, lee sin prejuicio La Vibora y La Trampa y convijertete a esta cruzada de salvaeion personal. La poesia ego centrica al lector cuan estimable es el ser humano, cuan inteligenetes y sensibles so elllos, cuan dignos de edmiracion son los objetos de este mundo, debe ceder el paso a una poessia más objetiva de simple descripcion de la naturaleza del hombre. Hasta cuando seguimos echandonos tierra a los ojos. El bohemio pa lido y emocionado debe quemar su sombrero de una vez por todas;el individuo no tiene importancia en la poesia moderna sino cono un objeto de an alisis psicologico; hablando en terminos muy generales nuestros poetroos romanticos sen cantores de opera, buenos, malos o excelentes a veces, geniales algunos como nuestro comun amigo Pablo, pero de todas maneras gentes que poseen una no cion restringida y finiquitada del trabajo artistico. $\mathbf{x z}$ L Los mas despejados de ellos creyeron xxzx haber terminado con el"cisne de nevado plumaje", pero en realidad no es asi. La generacion anterior a nosotros no hizo otra cosa. que terminar con el argumento mxux anecdota,sin preocuparse de revisar los principios mismos de la ciencia poe tica. Ellos se conformaron con lograr los mismos resultados que nuestros antecesores aunque con medios diferentes. La solemnidad yla gravedad dogmatica del arte del si.glo diecinueve siguio viva en ellos a pesar de las ensenanza de Picasso y de Jxax Dali. Me parece que el arte no puede ser otra cosa cue la reproducion objetiva de una realidad psicologica y ese fin no se consigu tratando de mostrar solo aquelloxxx que se considera rebestido de cierta di nidad. Un poema debe ser una especie de corte nas practicado en la totalidad del ser humano en el cual se vean todos los hifos y todos los nervios, las

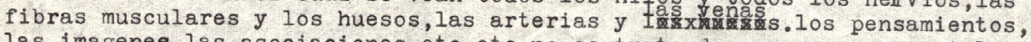
las imagenes, las asociaciones, etc, etc, no se trata de preparar un pastel más

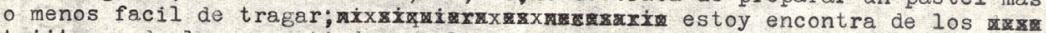
trisstes y de los angustiados, de la misma manera como estoy en contra de los bufones, estilo Huidobro.Tambien me revelo en contra de los profetas y en contra de los pensadores profeticos estilo T.S.Ellot. Estoy convencido de que e poeta no tiene el derecho de interpretar sino simplemente de describir friamente; el debe ser un ojo que mira a traves de un microscopio en cu yo extremo pulula una fauna microbiana; un ojo wcapaz de explicar lo que ve; esos es aproximadamente el asunto, dicho a toda carrera.

No se porque me he mebarcado en esta perorata absurda. Hace un dia hermos y como la belleza no hadejado de atraerme voy a despedirme para salir a dar una vuelta.Te aseguro que mi pr xima carta sera mucho mas ortodoja.Hasta luego querido Tomas.

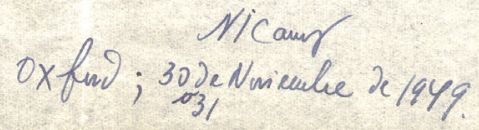




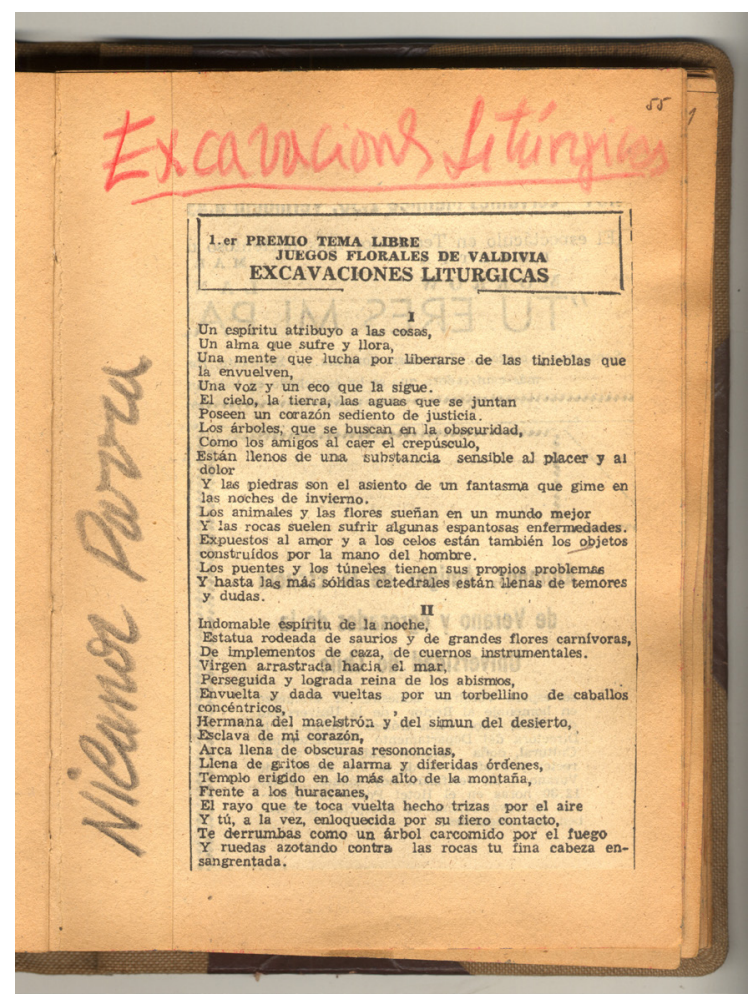

Fragmento de Excavaciones litúrgicas, 1954.

En esta misma revista, y fechadas en el año 1953, se publican con el título News From Nowhere y la presentación del poeta Ronald Kay, los siguientes poemas de Parra: "El reloj de Venancio", "La ceremonia de don Zacarías", "Improvisaciones más o menos premeditadas", "El Mar", "Díadas (20-vii-53), "News From Nowhere", "Misión cumplida", "La columna transparente", "Found poem", "La vuelta del viajero", "La mujer equis", "Memorias de un ataúd" y "Filosofía natural: Galileo Galilei, Isaac Newton, Albert Einstein".

\section{EXCAVACIONES LITÚRGICAS}

Con el título Excavaciones litúrgicas Parra obtiene el primer premio en tema libre de los Juegos Florales de la Semana Valdiviana, junto al poeta Manuel Martínez Labra, en febrero del año 1954. La obra consta de 21 poemas y fue publicada posteriormente con el título definitivo de Ejercicios retóricos en la revista Extremo Sur (ver respectiva entrada). 


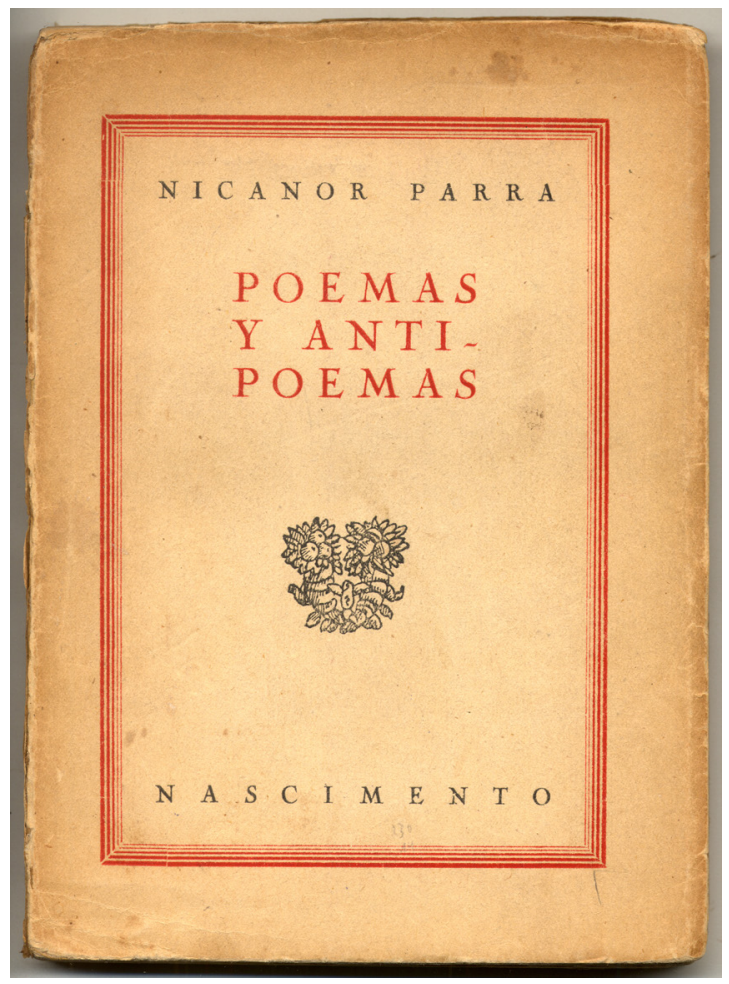

Primera edición de Poemas y antipoemas, 1954.

POEMAS Y ANTIPOEMAS. Santiago de Chile: Nascimento, 1954.

Poemas y antipoemas obtuvo en 1954 el premio del Concurso de Poesía patrocinado por el Sindicato de Escritores de Chile y en 1955 recibiría el Premio Municipal de Literatura de la Municipalidad de Santiago. Varios de los poemas que contienen habían sido recogidos previamente en antologías y revistas. Ya en Tres poetas chilenos, de Tomás Lago, se publican algunos de los poemas de la primera parte del libro: "Sinfonía de cuna", "Se canta al mar", "Hay un día feliz", "Es olvido". En la antología 13 poetas chilenos de Hugo Zambelli aparecen los primeros antipoemas propiamente tales: "La trampa", "Los vicios del mundo moderno", "La víbora".

El libro fue gestado por Nicanor Parra durante el prolongado silencio que se abre tras la publicación de Cancionero sin nombre en 1937. Durante estos años Parra se había consolidado a nivel profesional como profesor universitario de Mecánica Racional y había hecho cursos de postgrado en la Universidad de Brown (1943-1945) y Oxford (1949-1951). 
A su regreso a Santiago publicó en los Anales de la Universidad de Chile (1951) una selección de nuevos textos, trece en total, once de los cuales se incluirían luego en Poemas y antipoemas ("Hay un día feliz", "Es olvido", "Se canta al mar", "Defensa del árbol", "Catalina Parra", "San Antonio", "Autorretrato", "La víbora", "La trampa", "Los vicios del mundo moderno" y "Soliloquio del individuo"). La selección llevaba una larga presentación del poeta Enrique Lihn, la que se constituyó en el primer estudio importante de la antipoesía.

La publicación de Poemas y antipoemas fue consecuencia del insólito triunfo de Parra en el ya mencionado concurso del Sindicato de Escritores de Chile, al que envió por separado tres originales: "Cantos a lo humano y a lo divino", "Poemas" y "antipoemas". Cuenta el poeta:

Había que mandar los libros con un seudónimo, y en un sobre aparte el nombre verdadero, como siempre se hace. Entonces yo dije: "Aquí va a pasar lo que siempre pasa en los concursos: lo primero que hacen los jurados es abrir estos sobres para ver quiénes son los participantes y gozar a costillas de ellos". Yo sospechaba que eso podía ocurrir, que me podían ubicar y pillar y corría el riesgo de que la mafia literaria entrara en acción. Entonces puse como seudónimo Juan Nadie y en autor correspondiente a ese seudónimo puse Rodrigo Flores, el nombre de una persona muy conocida en Chile y amigo mío: campeón de ajedrez de la época y al mismo tiempo un prominente ingeniero. Un buen día anuncian que los tres primeros premios los había obtenido Rodrigo Flores. Y empezaron a llamar todos a Rodrigo para felicitarlo, quien por supuesto no entendía nada. Entonces rápidamente yo me presenté a la Biblioteca Nacional, donde operaba en ese tiempo el sindicato. Su presidente era el escritor Benedicto Chuaqui. Le dije: "Cómo está usted don Benedicto. Vengo a saludarlo y a agradecerle al sindicato este premio". "¿Qué premio?”, me preguntó. "¿Acaso no es usted Nicanor Parra?". "Sí”, le contesté, "yo soy el poeta premiado". "No", me dijo, "el poeta premiado es Flores". "Bueno", le expliqué, "yo mandé mis poemas con el nombre de Rodrigo Flores". Don Bene se quedó sorprendido y molesto y me desafió a demostrarle que yo era el autor. "No me cuesta nada”, le dije. “¿Usted tiene por ahí los poemas? Si quiere empiezo a recitarle el libro". Lo hice mientras él iba mirando los papeles. Después de un rato me dijo: "Sí, en realidad usted es el autor. Pero lo que hizo está al margen de la legalidad y lo que 
nosotros podemos hacer es declarar desierto el concurso, porque usted no cumplió con las bases". "Muy bien", le contesté, "está en su derecho y, por favor, hágalo, pero devuélvame los originales, porque estos poemas todavía no son publicables. Yo todavía tengo que trabajar en ellos". Ahí él tomó la ofensiva y me dijo: "Ah, no, se equivoca: este libro ya no le pertenece; de acuerdo con las bases del concurso, es propiedad del sindicato y este libro se publicará con o sin su beneplácito". Entonces yo le propuse que en esa circunstancia hiciéramos un solo volumen. Él accedió y ahí salió el título de Poemas y antipoemas. ${ }^{6}$

Durante el camino hacia Poemas y antipoemas, Parra ideó diferentes títulos de libros que nunca llegaron a publicarse. En Tres poetas chilenos se habla del futuro libro "La luz del día". En otras publicaciones, hay constancia de la próxima aparición del libro "Dos años de melancolía". Más adelante, Parra barajó, para los poemas que iba escribiendo, otros posibles títulos, entre los que destacan "Material de lectura", "Pensamientos varios", "A pan y agua", "Entre las nubes silba la serpiente", "Oxford 1950" y el libro inédito "Simbad el marino". El propio Parra frenaba sus impulsos por publicar: "Sobre todo porque yo sabía que cada libro de poesía que aparecía en Chile se medía con un solo metro: Neruda. Así como en la Física se habla de un ohm o de Newton, en poesía se hablaba de un Neruda y se trataba de ver cuántos nerudas había en cada poeta nuevo. Por eso me resistía y seguía puliendo, buscando, investigando. Tienes que publicar, me decían muchas veces, y yo contestaba: Todavía no estoy preparado. El mismo Neruda insistía en que me liberara de ese pasado. Es decir, estuve diecisiete años acachado con esa mercadería, en la sala de espera, en la sala de torturas". ${ }^{7}$

La elección de la palabra "antipoemas" que figura en el título del libro finalmente publicado en 1954 remite a la estancia de Parra en Oxford, donde escribió buena parte del libro:

Yo estaba en ese tiempo en la Universidad de Oxford, en Inglaterra, en el año 1950-51, escribiendo, puliendo libros, un mamo-

${ }^{6}$ Juan Andrés Piña, Conversaciones con la poesía chilena (Santiago: Pehuén Ediciones, 1990), 25-27.

${ }^{7}$ Ibídem, 25. 
treto. Un buen día pasé frente a una librería, me llamó mucho la atención un libro que se exponía en ese tiempo que estaba en la vitrina. El libro se llamaba Apoèmes, el autor un poeta francés, creo que Henri Pichette. Me llamó mucho la atención a mí esta palabra, apoemas. Pero, simultáneamente, me pareció —a pesar del acierto - una palabra que estaba a medio camino. Me dije: "¿Por qué no le pondría directamente antipoemas en vez de apoemas?". Me pareció la palabra antipoema más fuerte, más expresiva que la palabra apoema. Y, a continuación, di un segundo paso; me pareció que la palabra antipoema, sola, contaba nada más que la mitad de la historia, porque ¿dónde quedaban los poemas? Y entonces me pareció que el libro que yo estaba trabajando en ese tiempo debía titularse Poemas y antipoemas, o sea, en el libro debían aparecer dos objetos diferentes pero complementarios: los poemas tradicionales y, en seguida, este otro producto, estrambótico, más o menos destartalado, que se llama el antipoema. ${ }^{8}$

EJERCICIOS RETÓRICOS. En revista Extremo Sur n. ${ }^{\circ}$ 1, diciembre 1954.

Ejercicios retóricos fue escrito "entre el año 1943 y el año 1945", durante la estancia de Nicanor Parra en la Universidad de Brown, Rhode Island, donde cursó estudios de postgrado de mecánica avanzada. Nunca recogidos por Parra en las sumas antológicas de su poesía, estos poemas, sin embargo, constituyen un episodio fundamental en la brecha que se abre entre la publicación de Cancionero sin nombre, en 1937, y Poemas y antipoemas, en 1954. En esta etapa se destaca la gran influencia que, después de García Lorca, ejerció sobre Parra la lectura de la obra de Whitman. Ejercicios retóricos consta de 21 poemas y se trata del mismo texto que con el título de Excavaciones litúrgicas obtuvo el primer premio en el tema de poesía libre en los Juegos Florales de la Semana Valdiviana en 1954.

El año 1970 se publicará en una separata de la revista Aisthesis, del Centro de Investigaciones Estéticas de la Universidad de Chile, una entrevista de Alfonso Calderón a Nicanor Parra donde se aclara que el título de esta obra es Ejercicios respiratorios. Esta obra no volvió a publicarse hasta el año 2006, cuando se integró al primer volumen de Obras completas \& algo + .

\footnotetext{
${ }^{8}$ Piña, Conversaciones, 25.
} 


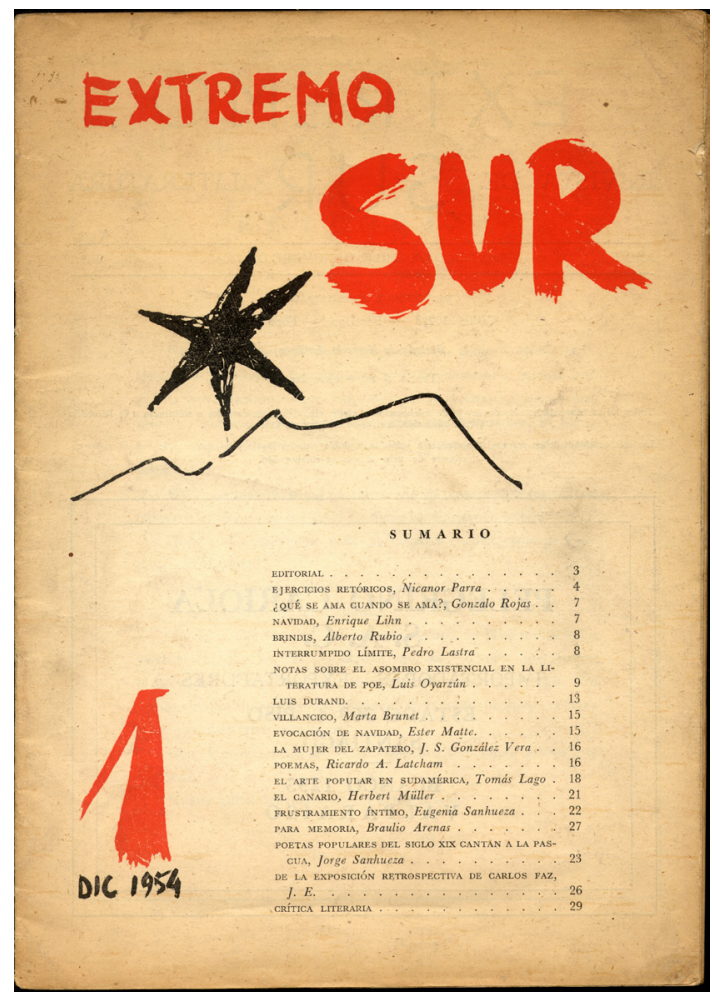

Portada revista Extremo Sur n. ${ }^{1} 1,1954$, donde se publicó Ejercicios retóricos.

“POETAS DE LA CLARIDAD”. En revista Atenea n. . 380-381, 1958.

El texto corresponde a la ponencia presentada por Nicanor Parra en el Primer Encuentro de Escritores Chilenos, organizado por Gonzalo Rojas en Concepción el año 1958. Se trata de un documento importante para comprender la evolución de Parra entre la publicación de Cancionero sin nombre y Poemas y antipoemas.

LA CUECA LARGA. Santiago de Chile: Editorial Universitaria, 1958. Ilustraciones de Nemesio Antúnez.

Un par de años después de la primera edición de "La cueca larga", en 1960, el libro volvió a ser reeditado por la misma editorial en un formato que era parte de una colección de la que también formaban parte Pablo de Rokha, Fernando Alegría y Ernesto Cardenal. La edición incluía un disco de 45 RPM que registró una versión recitada por Roberto 


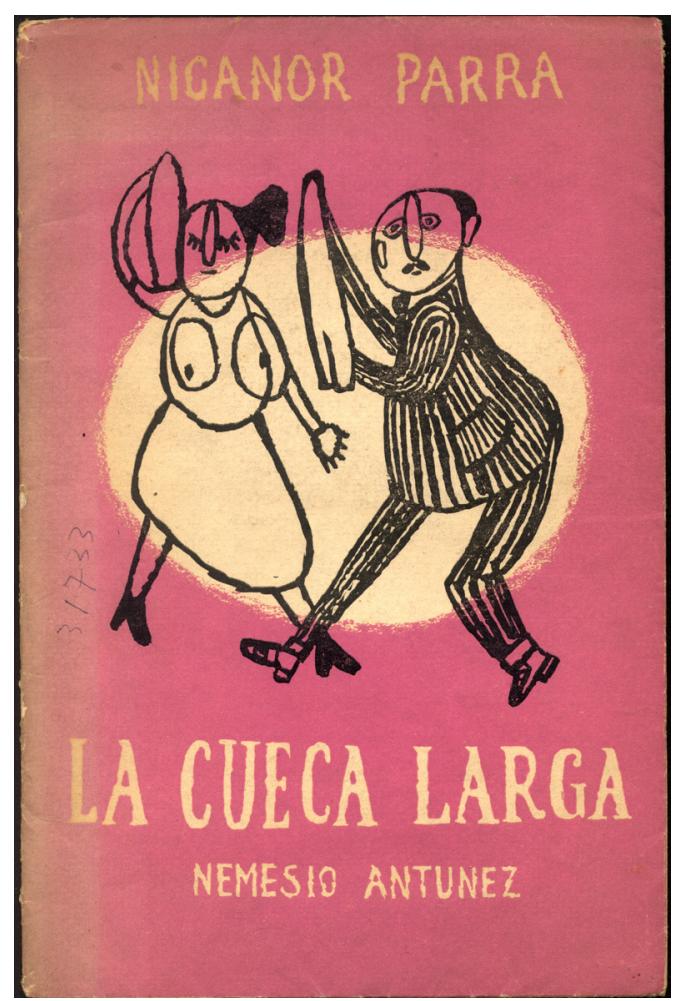

Primera edición de La cueca larga, 1958, con ilustraciones de Nemesio Antúnez.

Parada de "Coplas del vino", "El chuico y la damajuana" y "Brindis", con acompañamiento a la guitarra de Violeta Parra. En el mismo disco ella interpreta al menos dos de las composiciones de La cueca larga: la ya mencionada "El chuico y la damajuana" y "La cueca larga de los Meneses", una versión abreviada de la propiamente llamada "La cueca larga". En ese tiempo, Nicanor Parra tenía en proyecto un libro que nunca concretó, "Tonadas y cuecas", que, sin embargo, sirvió de base para que Violeta empezara a trabajar componiendo la letra y la música de sus propias canciones.

VERSOS DE SALÓN. Santiago de Chile: Nascimento, 1962.

Versos de salón recoge en su cubierta algunos pasajes elogiosos sobre el autor, uno de ellos firmado por Alone y publicado en El Mercurio en junio del año 1957. Muchos de los poemas de Versos de salón habían sido ya publicados. En una conversación con José Donoso, en julio de 


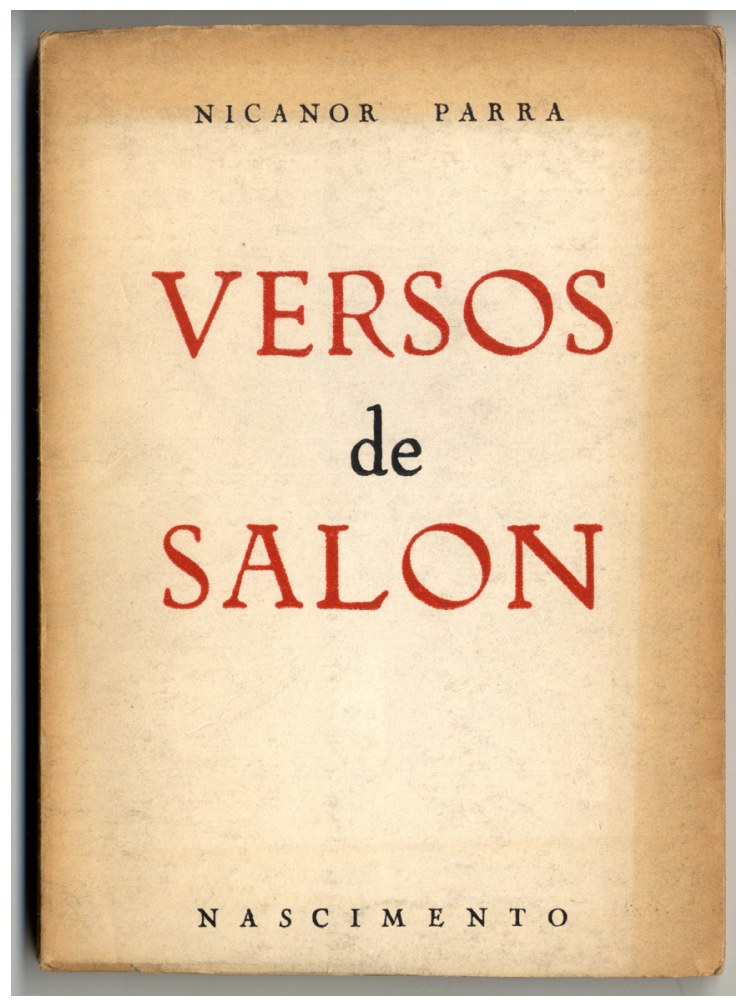

Primera edición de Versos de salón, 1962.

1960, Parra asegura tener listo este poemario desde el año $1958 .{ }^{9}$ Otros títulos con los cuales pensaba publicar esta obra son "Baile sobre una tumba", "Licencia poética", "Pan, pan, vino, vino", "Poesía para poetas", "Las cuatro operaciones", "El gato montés" y "Nebulosa 1960".

DISCURSOS / PABLO NERUDA / NICANOR PARRA. Santiago de Chile: Nascimento, 1962.

El 19 de marzo de 1962, la Facultad de Filosofía y Educación de la Universidad de Chile, en sesión pública celebrada en el Salón de Honor, recibió a Pablo Neruda en calidad de miembro académico, en reconocimiento a su vasta labor poética de categoría universal. El acto fue presidido por el rector Juan Gómez Millas; por el decano de la facultad, Eugenio González, y por el secretario general, Álvaro Bunster. Nicanor Parra, miembro docente de la corporación, tuvo a su cargo el discurso

\footnotetext{
${ }^{9}$ Parra, Obras completas I, 940.
} 


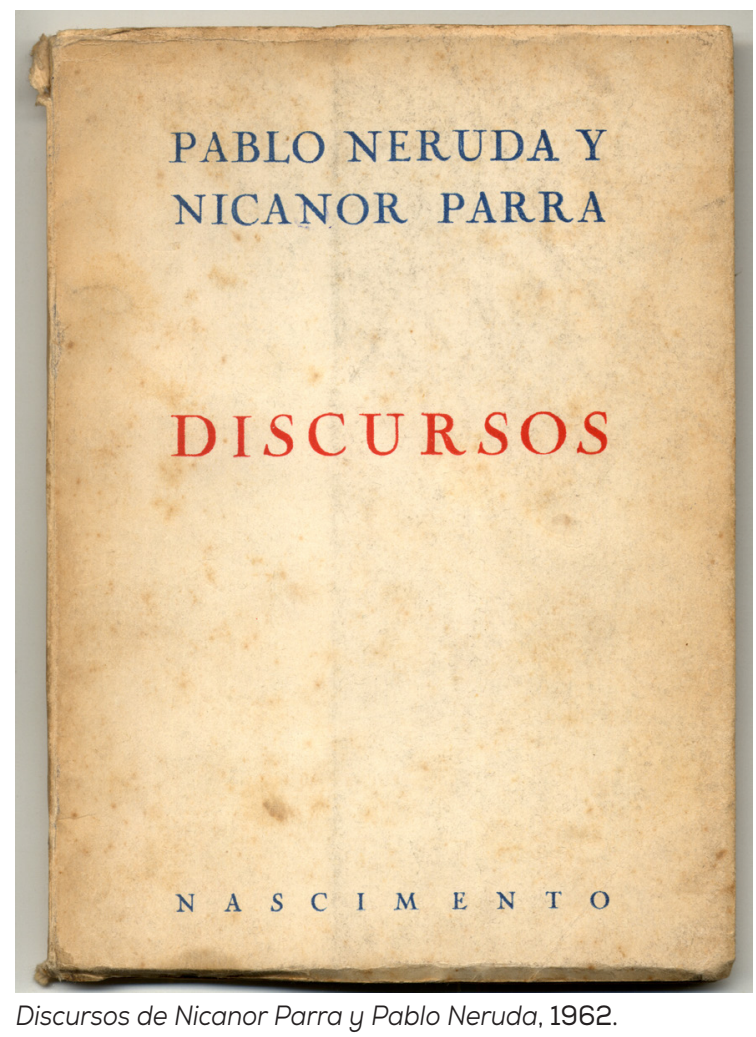

de recepción. El discurso de Pablo Neruda se tituló "Mariano Latorre, Pedro Prado y mi propia sombra", y Hernán Loyola dice de él que "condensa, desde una perspectiva madura y serena, las ideas fundamentales de Neruda no sólo sobre su poesía, sino sobre el significado del hacer poesía en Chile".

El texto de Parra se tituló: "Discurso de bienvenida en honor de Pablo Neruda". Y comienza: "Hay dos maneras de refutar a Neruda: / una es no leyéndolo, la otra es leyéndolo de mala fe. / Yo he practicado ambas, / pero ninguna me dio resultado...".

DOS POEMAS / NICANOR PARRA / DEUX POÈMES. Genève: Editions Librairie Rousseau, 1963.

Edición bilingüe castellano-francés de los poemas "Soliloquio del individuo" y "El pequeño burgués". Traducción de Emile Hiltbrand. Edición de 400 ejemplares numerados en papel chiffon vergé filigrané "Arches". Plegado. 


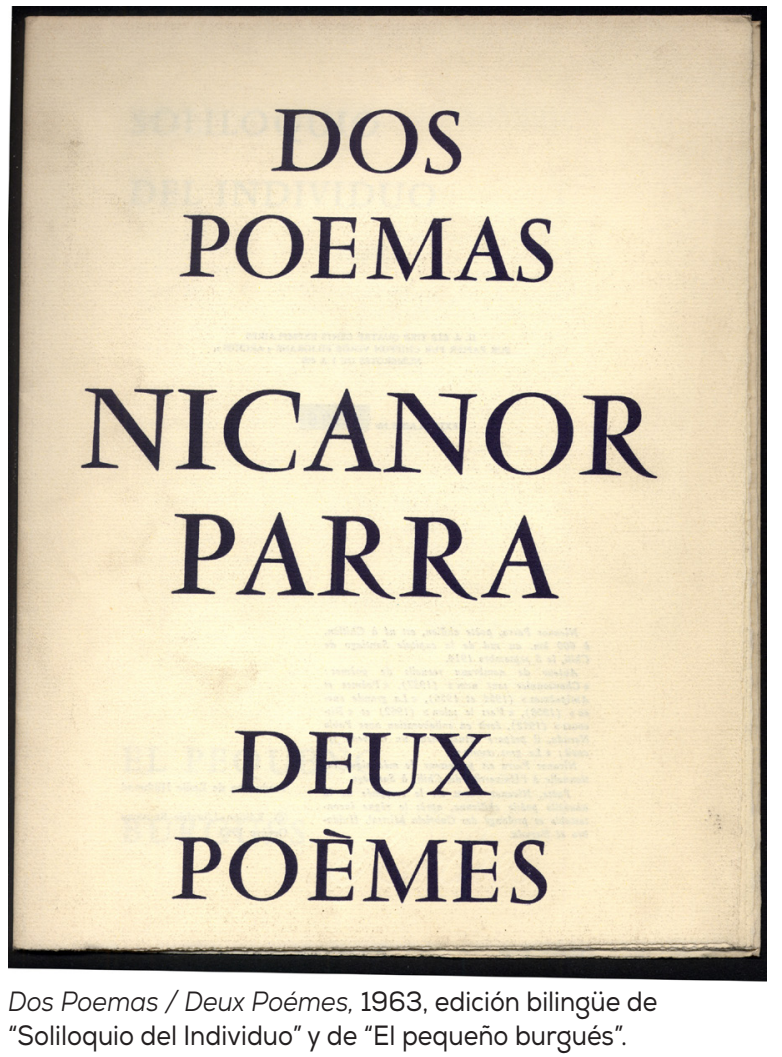

“MANIFIESTO”. Santiago de Chile: Nascimento, 1963.

Este poema se publicó originalmente en forma de cartel plegado (40 x $77 \mathrm{~cm}$ ), con diseño de la pintora española Roser Bru. Al pie del poema, se puede leer la siguiente indicación: "Del libro Poemas prácticos, de próxima publicación". Este libro nunca llegará a publicarse, y "Manifiesto" integrará, en 1969, la sección "Otros poemas", de Obra gruesa.

En entrevista con el poeta uruguayo Mario Benedetti, Nicanor Parra dice lo siguiente:

Bueno, es un poema que lo viví y lo pensé por allá por el año 1960. En realidad el "Manifiesto" lo empecé a trabajar mucho antes. En este poema además hay otra idea: yo quería ver si era posible hacer una poesía tipo ensayo, una poesía ensayística, a base de ideas. La respuesta es positiva: aunque este poema sea un 


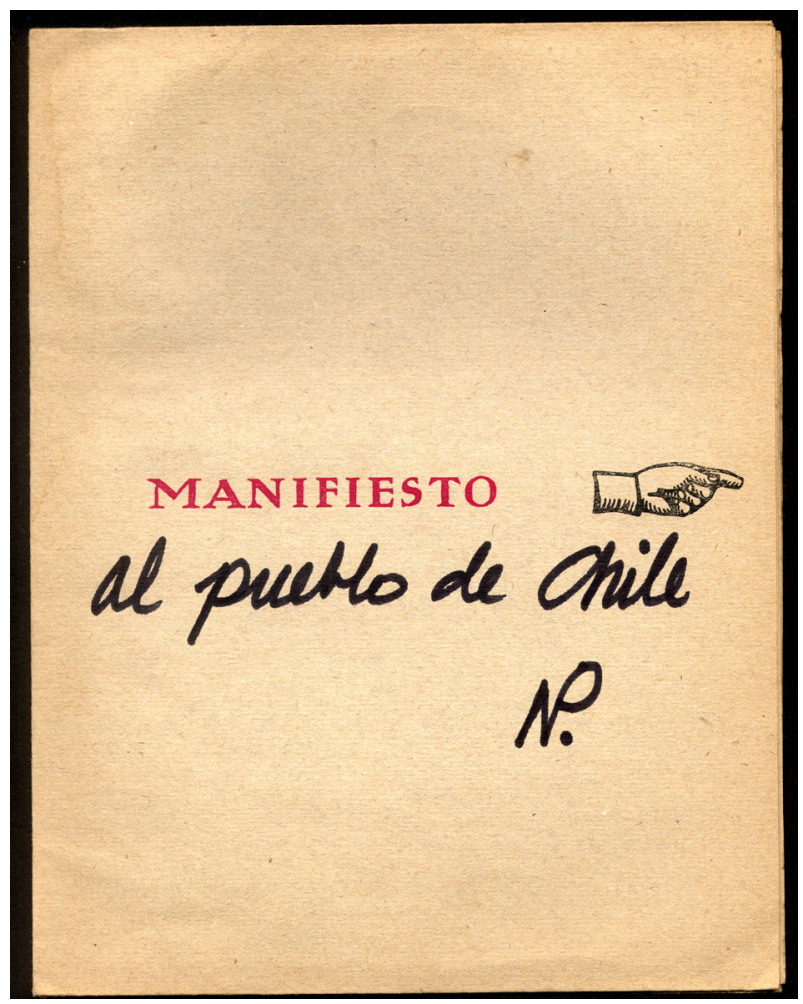

“Manifiesto", cartel plegado con diseño de Rosen Bru, 1963.

poema frustrado, un poema a medio camino, en todo caso está a medio camino, o sea que está en alguna parte, no se quedó en el punto de partida. Es posible trabajar la poesía a base de ideas; así parece. O sea, poner las ideas en primer plano; y las sensaciones, las impresiones, la poesía propiamente tal, en segundo plano. ${ }^{10}$

CANCIONES RUSAS. Cuaderno apartado de la revista Mundo Nuevo $\mathrm{n}^{\circ}$ 3, septiembre, 1966.

Esta revista se publicaba en París y era dirigirá por Jean-Yves Bouedo. El texto está en castellano y en ella la obra se publica por primera vez en su integridad.

${ }^{10}$ Mario Benedetti, "Nicanor Parra o el artefacto con laureles", en revista Marcha, 17 de octubre de 1969, 13-15. 


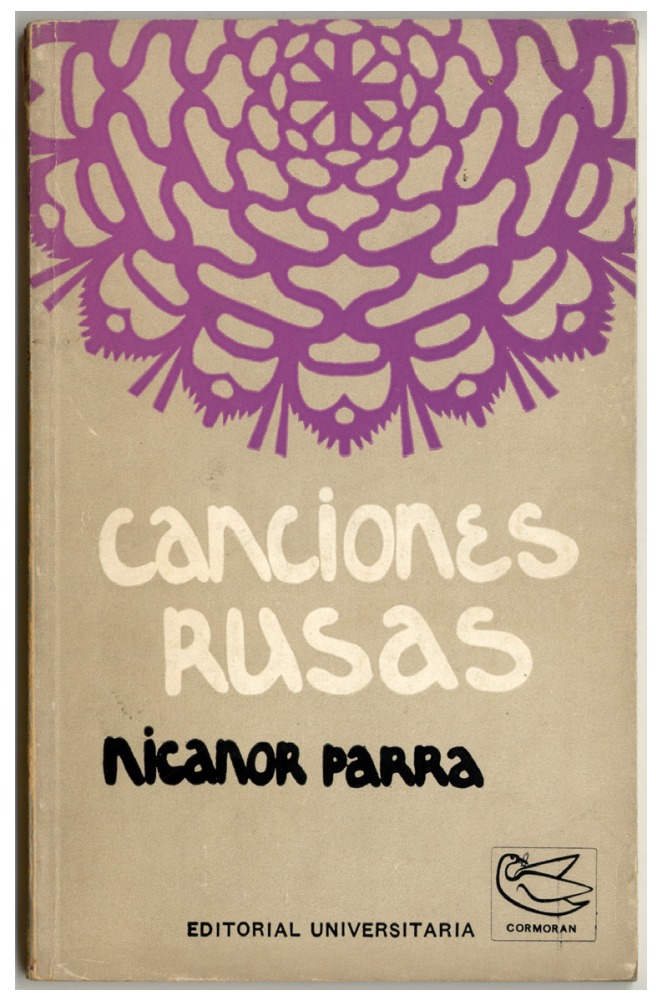

Primera edición en forma de libro de Canciones rusas, 1967.

CANCIONES RUSAS. Santiago de Chile: Editorial Universitaria, 1967.

Proyectó la edición Mauricio Amster. Cubierta de Susana Wald. Canciones Rusas es el volumen $\mathrm{n}^{\circ} 3$ de la colección Letras de América, que dirigía Pedro Lastra.

En una entrevista publicada en Portal con motivo de la publicación del libro, declara Parra: "Ahora mis últimos poemas, Canciones rusas, son ya la manifestación de un alma integrada completamente a su época. El hombre habla con Canciones rusas desde su rotundo centro de gravedad". ${ }^{11}$

El primer viaje de Parra a la Unión Soviética tiene lugar en 1958, tras la publicación de La cueca larga, y se encuadra en el marco de una

${ }^{11}$ Parra, Obras completas I, 951. 


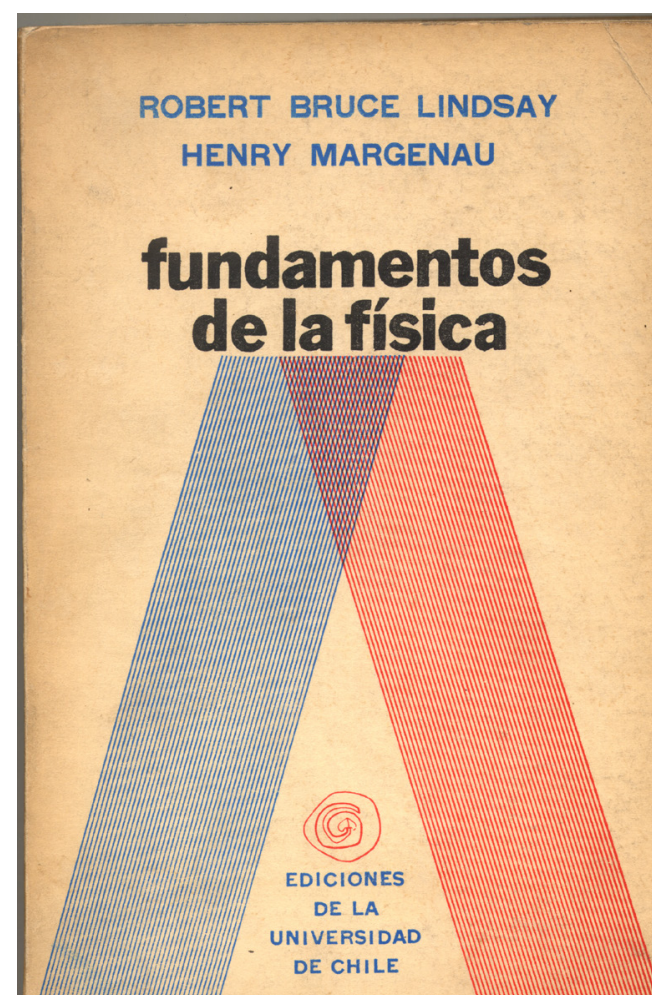

Fundamentos de la fisica, de Lindsay y Margenau, 1969. Traducción de Nicanor Parra.

prolongada gira que lo llevaría, invitado por diversas organizaciones internacionales de escritores, a Viena, Estocolmo, Moscú, Pekín, Roma y Madrid. A su regreso de ese largo viaje, Parra declarará: "Espero que mi poesía torne a la naturaleza humana, a la ternura, al amor". ${ }^{12}$

En el n. ${ }^{\circ} 5$ de la revista Portal (julio de 1967), Pablo Neruda publica un poema titulado: "Una corbata poética para Nicanor", fechado el 19 de noviembre de 1966. El poema — estructurado gráficamente como una corbata - celebra al antipoeta que "hace / vino / de / estos / frutos / brutales / que / brotan / de / su / propia / parra, / o de / la burla / que / se hace / racimo / o / de / la bofetada / que / es / un / súbito / fruto / del / parrón / o parral". El texto hace una implícita alusión al propio manifiesto de Neruda, "Sobre una poesía sin pureza", publicado en la revista Caballo Verde para la Poesía en el año 1935.

12 Parra, Obras completas I, 951. 


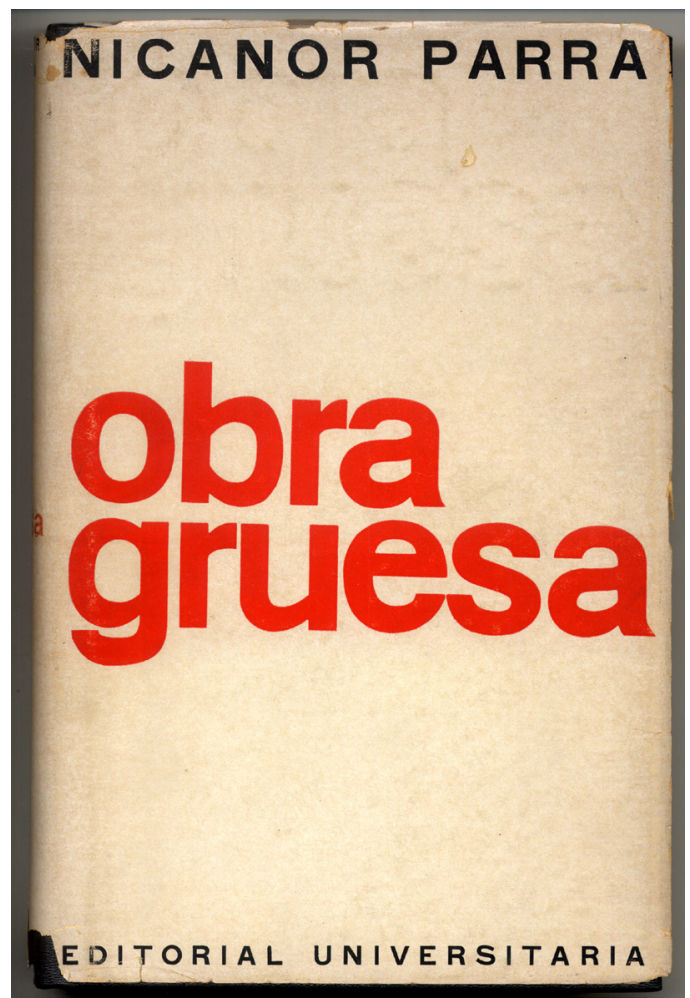

Primera edición de Obra gruesa, 1969.

FUNDAMENTOS DE LA FÍSICA, de Robert Bruce Lindsay y Henry Margenau. Traducción de Nicanor Parra Sandoval. Santiago de Chile: Ediciones de la Universidad de Chile, 1969.

Texto traducido por Nicanor Parra en su papel de profesor de física y director del Departamento de Física de la Facultad de Filosofía y Educación de la Universidad de Chile. Edición al cuidado de Félix Schwartzmann.

OBRA GRUESA. Santiago de Chile: Editorial Universitaria, 1969.

Considerada una de las mejores ediciones de sus obras, fue publicada en el mismo año en que se le otorga el Premio Nacional de Literatura. Incluye los libros de poemas publicados hasta entonces - Poemas y antipoemas (1937-1954); La cueca larga (1958); Versos de salón (1954-1962) y Canciones rusas (1964-1967) — y tres secciones de poe- 


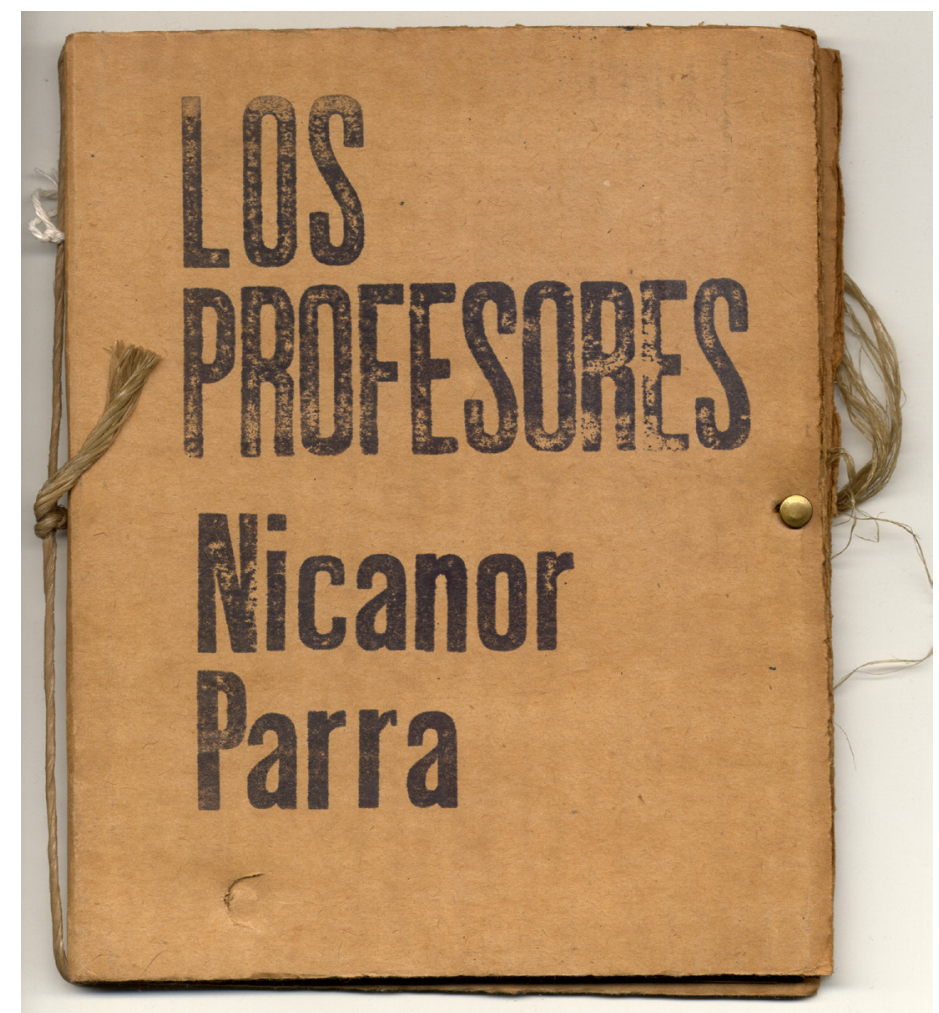

Los profesores, 1971. Una de las piezas más difíciles de encontrar de la extensa bibliografia de Parra.

mas en su mayor parte inéditos: "La camisa de fuerza" (1962-1968), "Otros poemas" (1950-1968) y "Tres poemas" (1937-1954). Entre estos, "Acta de independencia", "Test", "Padre nuestro" y "Me retracto de todo lo dicho" (en "La camisa de fuerza"), así como "Manchas en la pared", "Consultorio sentimental", "Me defino como hombre razonable", "Pensamientos", "En el cementerio", "Ponchartrain Causeaway" (en "Otros poemas") habían sido publicados previamente, bajo el epígrafe "Poems from Ejercicios respiratorios" (1964-1966), en la antología bilingüe Poems and Antipoems (New York: New Directions, 1967), editada por Miller Williams, con traducciones de Fernando Alegría, Lawrence Ferlinghetti, Allen Ginsberg, James Laughlin, Denise Levertov, Thomas Merton, W.S. Merwin, Patricia Rachal, Miller Williams y William Carlos Williams.

En la última hoja del libro se puede leer lo siguiente: "Algunas de las fotografías que reproducimos en esta obra han sido rescatadas de re- 
vistas y no se dispone de los originales. Si bien carecen de la nitidez necesaria, ellas conservan, no obstante, un valor testimonial considerable".

LOS PROFESORES. Nueva York: Antiediciones Villa Miseria, 1971.

Este poema constituye una de las piezas más difíciles de encontrar de la extensa bibliografía de Nicanor Parra. Pertenece a la serie Poetas Mayores, editada por Elena Jordana. La edición de Los profesores fue de 250 ejemplares y cada uno está numerado y firmado por Parra. No es un libro de aspecto tradicional. Sus tapas son de cartón corrugado y el poema está impreso (aparentemente en una máquina Multilith) y adherido con un cáñamo a sus tapas. La impresión de las tapas se hizo con timbres de goma. Es lo que podríamos llamar una edición artesanal, confeccionada a mano con materiales de desechos o de escaso valor comercial, en un concepto de antiedición, es decir, una propuesta en contra de la producción industrial de best sellers y de libros en tirajes de miles o millones de ejemplares. La ilustración final de un hongo atómico hace alusión a la civilización del siglo XX. De ahí la necesidad de que cada uno fuese numerado y firmado por el autor. En la contraportada se puede leer el texto: "Primera condición / de toda obra maestra / pasar inadvertida".

POEMAS DE EMERGENCIA / EMERGENCY POEMS. Nueva York: New Directions, 1972.

Primera edición bilingüe castellano-inglés. Es una antología de textos editados e inéditos, algunos de ellos publicados en el otoño de 1970 en la Revista Chilena de Literatura, bajo el título de "Palabras obscenas"; entre ellos, "Proposiciones", "Entonces", "Salta a la vista", "Supongamos que es un hombre perfecto", "Un sujeto de malos antecedentes", "Si el Papa no rompe con USA", "Yo, Jehová, decreto", "No creo en la vía pacífica" y "Viva Stalin".

POESIA RUSA CONTEMPORÁNEA. Santiago de Chile: Ediciones Nueva Universidad, 1971-1972. Versiones de Nicanor Parra, Premio Nacional de Literatura. Edición bilingüe.

En una nota previa al prólogo, la Vicerrectoría de Comunicaciones de la Universidad Católica de Chile, en nombre de Ediciones Nueva 
Universidad, explica lo siguiente sobre esta antología de poesía rusa contemporánea:

Proyectó la edición de este libro, Cristián Santa María y diseñó la portada, Guillermo Tejeda.

(...)

Sobre la base de una primera versión literal al castellano, preparada por José Vento, Parra trabajó en Moscú durante el año 1964, contando con la colaboración de dos asesores lingüísticos: Agustín Manzo y Vicente Arana.

(...)

El ambicioso proyecto —en confesión del autor- no habría cristalizado sin el entusiasmo de una de las poetisas antologadas, Margarita Aliguer. Su participación no terminó en aquella época, pues suya fue la gestión para que la Universidad Católica de Chile recibiera la autorización para realizar esta nueva edición. La original, también bilingüe, fue publicada por Editorial Progreso, de Moscú, sin alcanzar una real difusión en América Latina. ${ }^{13}$

La obra tiene prólogo de Vladimir Ognev y está ilustrada con una fotografía de cada poeta antologado y una breve biografía.

ARTEFACTOS. Santiago de Chile: Ediciones Nueva Universidad, 1972.

La edición original de Artefactos no es un libro. Es una caja de cartón de 19 x 14,3 centímetros de base y de 4,5 centímetros de altura, que contiene dos bloques separados de 121 tarjetas postales en cada lado, todas de 13,2 x 9 centímetros. Cada una de las tarjetas lleva en su anverso un "artefacto" y en reverso la leyenda tradicional de las tarjetas postales para ser enviadas por correo tradicional.

La caja de los Artefactos de 1972 es resultado de un trabajo realizado en colaboración con el diseñador gráfico Juan Guillermo Tejeda, autor de gran parte de las ilustraciones. Fue idea de Cristián Santa María, director en aquel tiempo de Ediciones Nueva Universidad, proponer a Tejeda para esta tarea. "Recibí los textos escritos con bolígrafo azul - recuerda Tejeda - y me puse a componer postales en blanco y negro, con mucho collage y algunos dibujos, así como tipografías diversas.

${ }^{13}$ Nicanor Parra (traductor), Poesía rusa contemporánea (Santiago de Chile: Ediciones Nueva Universidad, 1972). 


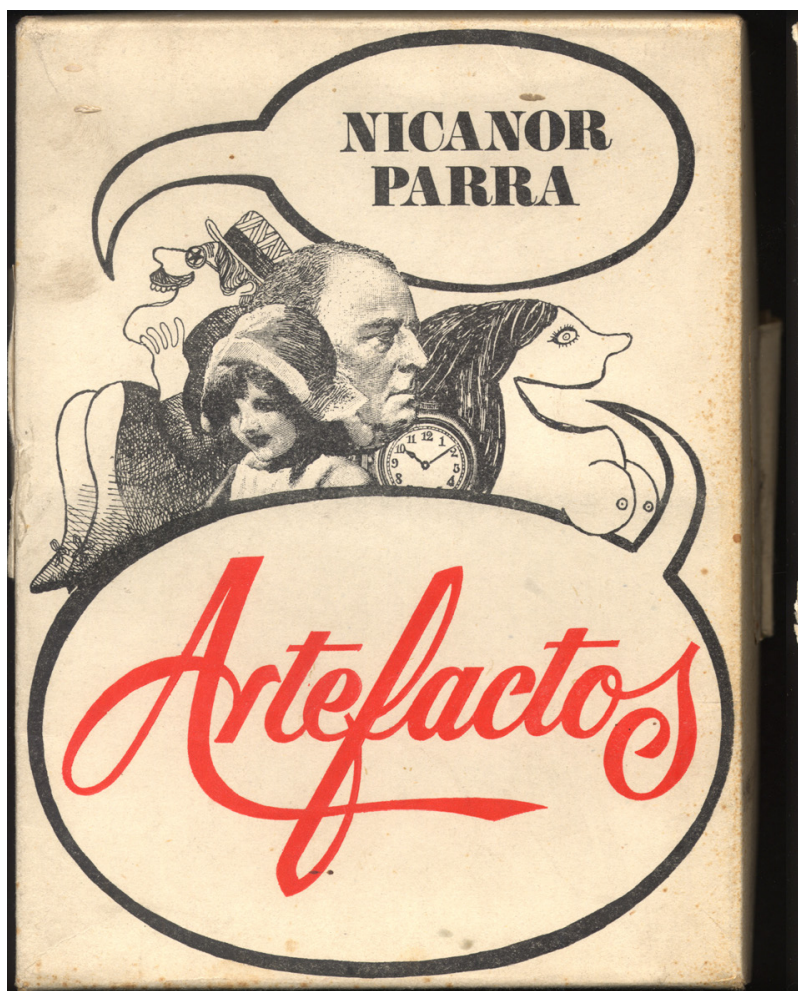

Primera edición de Artefactos, 1972, caja donde los poemas se diseñaron sobre tarjetas postales.

Recuerdo esas noches pegoteando textos o letras sobre una mesa un poco bamboleante que yo mismo me había construido". ${ }^{14}$

Tejeda iba recibiendo más y más artefactos de Parra. Tejeda y Santa María convinieron, así, en reproducir los últimos artefactos en la propia caligrafía del poeta. Esto explica que buena parte de las postales no estén compuestas tipográficamente ni se acompañen de ninguna imagen. Se sabe que muchos artefactos fueron considerados demasiado "explosivos" para el ambiente político que vivía el país y el autor los retiró de la publicación, y probablemente se encuentran en otras obras editadas en años posteriores. Uno de ellos era el siguiente: "Me cago en Marx".

En las Conversaciones con Nicanor Parra, de Leonidas Morales, grabadas en mayo de 1970, Parra da cuenta de un proyecto - el de "las

${ }^{14}$ Parra, Obras completas I, 982. Tejeda ahonda en la composición de Artefactos en un artículo de su autoría en este mismo número de Estudios Públicos. 
tarjetas de Pascua"- que no llegó a ver la luz tal y como él lo describe, pero que guarda evidentes afinidades con la caja de Artefactos de 1972:

Estas tarjetas están hechas a base de recortes, en línea con $E l$ Quebrantahuesos. Se junta toda esa literatura de Pascua y Año Nuevo que se produce en cantidades industriales: tarjetas convencionales, avisos que se publican en los diarios. Mientras, antes se han ido recortando durante el año las imágenes, las láminas referentes; pongamos por caso a la guerra de Vietnam, al genocidio, a Biafra. Es un collage específico y muy nítido, que consiste en hacer chocar una frase, un texto bastante ridículo y convencional, por ejemplo: "Nuestros más sinceros deseos de felicidad para usted y los suyos". Y encima de este texto, supongamos, esa fotografía que se hizo clásica el año pasado, de una autoridad survietnamita que está disparando a boca de jarro una pistola a un muchacho norvietnamita que ha caído prisionero. Estas "tarjetas de Pascua" son entonces un collage de trascendencia social algunas veces y otras de trascendencia metafísica. ${ }^{15}$

En otra entrevista de 1970, el poeta relacionaba los artefactos no sólo con la ingeniosidad de los avisos comerciales, sino que también con un género de escritura que había conocido en Estados Unidos y que dio lugar a un contenido más político: "Me llama mucho la atención la literatura mural estudiantil. Los grafitis revolucionarios". Recuerda ejemplos como: "Death has no future" y "Today is pig, tomorrow is bacon". A continuación Parra afirma: "El libro que estoy por publicar en Chile - bueno, no se trata de un libro, sino de una serie de tarjetas postales que vienen en una caja- es un conjunto de grafitis. Yo los llamo artefactos, también podría llamarse literatura de water closet o un libro de poemas: W.C. Poems". ${ }^{16}$

El escritor argentino Ricardo Piglia ha dicho de los artefactos: "Los Artefactos de Parra son a la literatura en lengua española lo que la obra de Duchamp ha sido para el arte contemporáneo". ${ }^{17}$

${ }^{15}$ Morales, Conversaciones.

${ }^{16}$ Parra, Obras completas I, 989-990.

${ }^{17}$ The Clinic, "Ricardo Piglia: 'Neruda es el poeta de las efemérides; Parra es el poeta de todos los días"”, 2 de diciembre de 2011, www.theclinic.cl/2011/12/02/“neruda-es-el-poeta-de-las-efemerides-parra-es-el-poeta-de-todos-los-dias"/ 


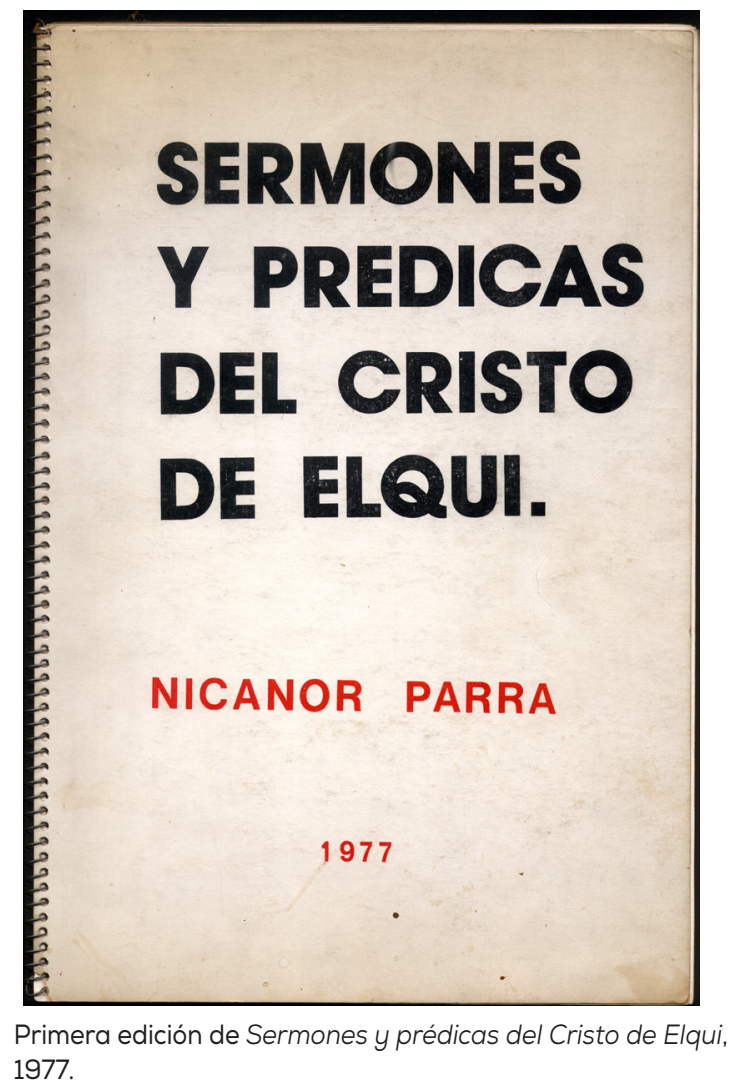

SERMONES Y PRÉDICAS DEL CRISTO DE ELQUI. Santiago de Chile: Galería Época y Estudios Humanísticos de la Facultad de Ciencias Físicas y Matemáticas de la Universidad de Chile, 1977.

Edición numerada de 500 ejemplares, algunos de ellos firmados. Lleva tres fotografías del Cristo de Elqui atribuidas a Heliodoro Torrente, y reproduce la cubierta de "La promesa y la vida de El Cristo de Elqui” (1948).

SERMONES Y PRÉDICAS DEL CRISTO DE ELQUI. Segunda edición. Valparaíso: Editorial Ganymedes, 1979.

Esta segunda edición incorpora la presentación inicial ("Y ahora con ustedes...", seguida de "Gracias por los aplausos..."), que no figuraba en la primera. En la segunda edición sólo se mantiene una de las tres fotografías del Cristo de Elqui. 


\section{NUEVOS SERMONES Y PRÉDICAS DEL CRISTO DE ELQUI.} Valparaíso: Editorial Ganymedes, 1979.

“EL ANTI-LÁZARO”. Valparaíso: Gráfica Marginal, 1981.

Impresión de 36 por 26 centímetros que reproduce holográficamente el manuscrito del poema y al reverso lo muestra escrito a máquina. Incluido posteriormente en Hojas de Parra (1985).

“EL HOMBRE IMAGINARIO”. Valparaíso: Gráfica Marginal, 1982.

Reproducción holográfica de 36 por 26 centímetros del manuscrito original, datado en Conchalí en noviembre de 1979.

POEMA Y ANTIPOEMA A EDUARDO FREI. Santiago de Chile: Editorial América del Sur, 1982.

Fue el primer texto publicado por América del Sur, editorial fundada por el poeta César Soto Gómez, que imprimió este poema con esmero en un cuadernillo de ocho páginas en papel rugoso y grueso, satinado, e hizo una tirada de doscientos ejemplares firmados por el autor.

ECOPOEMAS. Valparaíso: Gráfica Marginal, 1982.

Es un pliego de ocho páginas. Los nueve poemas se reproducen holográficamente (con la caligrafía del autor) y se dan firmados en "Conchalí 82". La edición está ilustrada con una viñeta en la cubierta $\mathrm{y}$, en la página cuatro, un grabado de José Guadalupe Posada representa unas calaveras en bicicleta, empleadas ya para una de las postales de los Artefactos de 1972, donde se leía debajo: "La muerte es un hábito colectivo".

CHISTES PARAA DESPISTAR A LA POEÆĆA POESÍA. Santiago de Chile: Gráfica Marginal, 1982.

Primera edición de Chistes para despistar a la poesía, realizada en formato pequeño (12 por 12 centímetros), en papel de color rosado e ilustrada con grabados anónimos. Algunos ejemplares fueron firmados por el autor. 
(Herto no te levautes de fe tumba

f qui quariés con resucitar

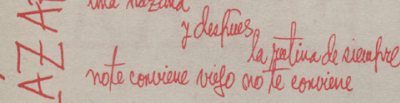

1 vargullo la bangre la avaricia tetiransa del deseo neuéreo

los dolores que causa la muler el exigura del lieuspo

- les artetrariedades del eshacio recafacula musto recahacila

queno pecuerdas cémopra la logs? ala menor dificuttal explatabas en juifpoperios a diestra y simestra tras te molestaba

no pisislias yo

ni ta presucia de ta profina Soubur

wels menoria velojpals menvian! tuy corazón ers un numbu de escoulus - istog citando tus hrofics escritos y delu alua no quedaba nada
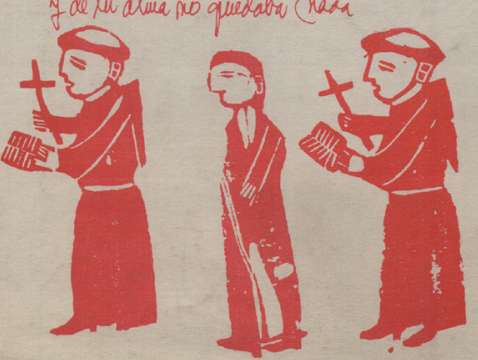

a qué volver entwices al nufierno del Daute i para que pe refila la enuedia? quí diaria cquedia ni que $8 / 4$ vocupres de luces - es hefismos? cebo hera cazar lauchas golosas ue ri que setera disharate vorfelor cafaner eres felier tur tur Sefulcrone te falli made ruete de tos neas de colves abo-aló me ertás lscuchaurs?

giviei no va a, freferior alos Caricias de una hobrase prostilute nadie que este lu Aus 5 rentides salvo que taus pacto cond diablo seque durmieabo huluers tigus durmeludo siu vos aquitarazos de la dude.

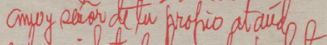
bur ta quieluat de ba noche perfecta lipre de helo y hafa como ai numia nubieras estado des fiento no pericites hor nung un motivo ono tives hara que honerte peroroso cowo difgel hoeten tious lora ta nuerto per delaule

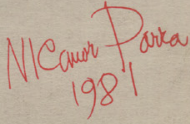

"Anti-Lázaro", 1981. Reproducción holográfica del manuscrito, 36 por 26 centimetros. 


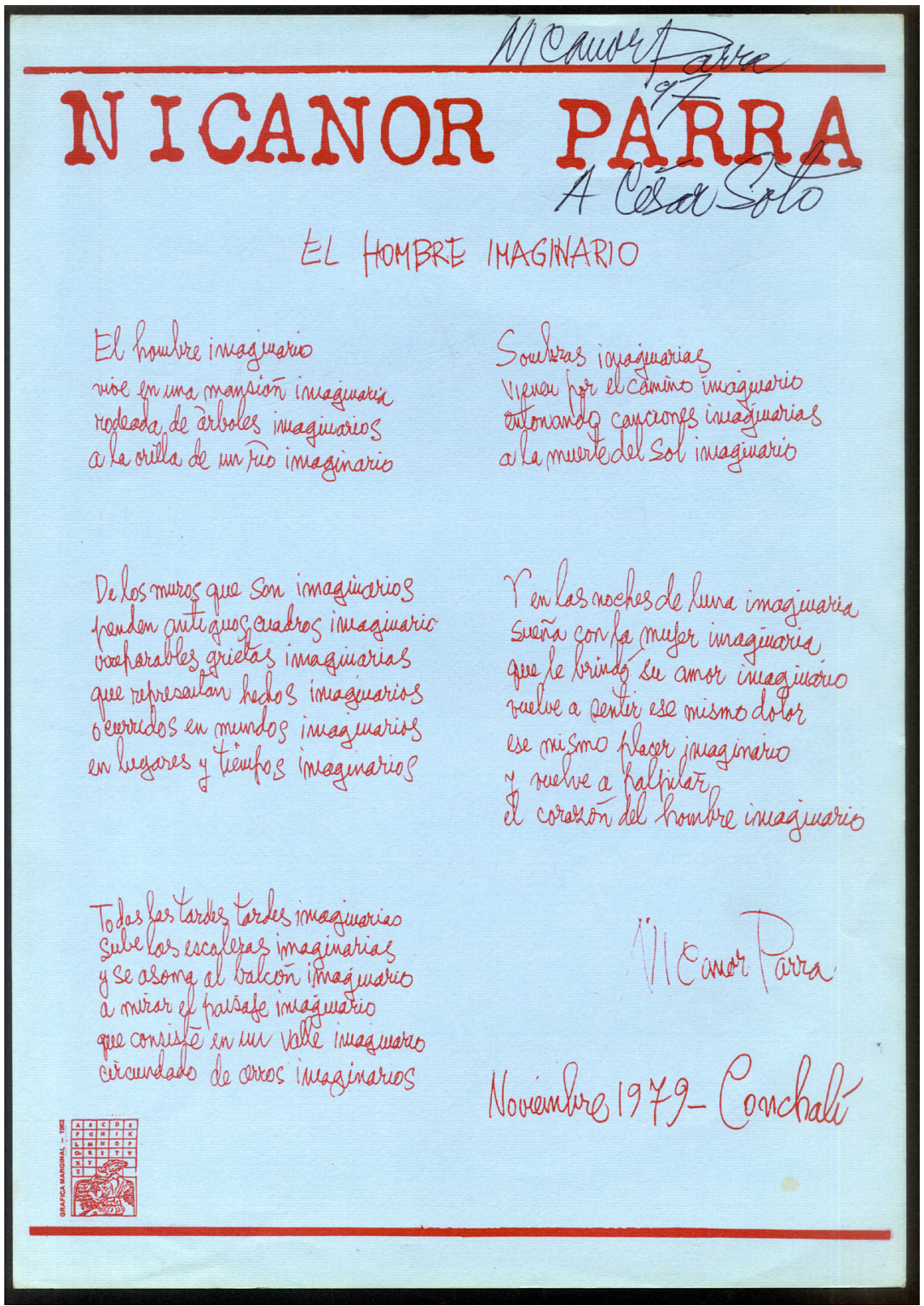

"El hombre imaginario", 1982. Reproducción holográfica del manuscrito, 36 por 26 centímetros. 


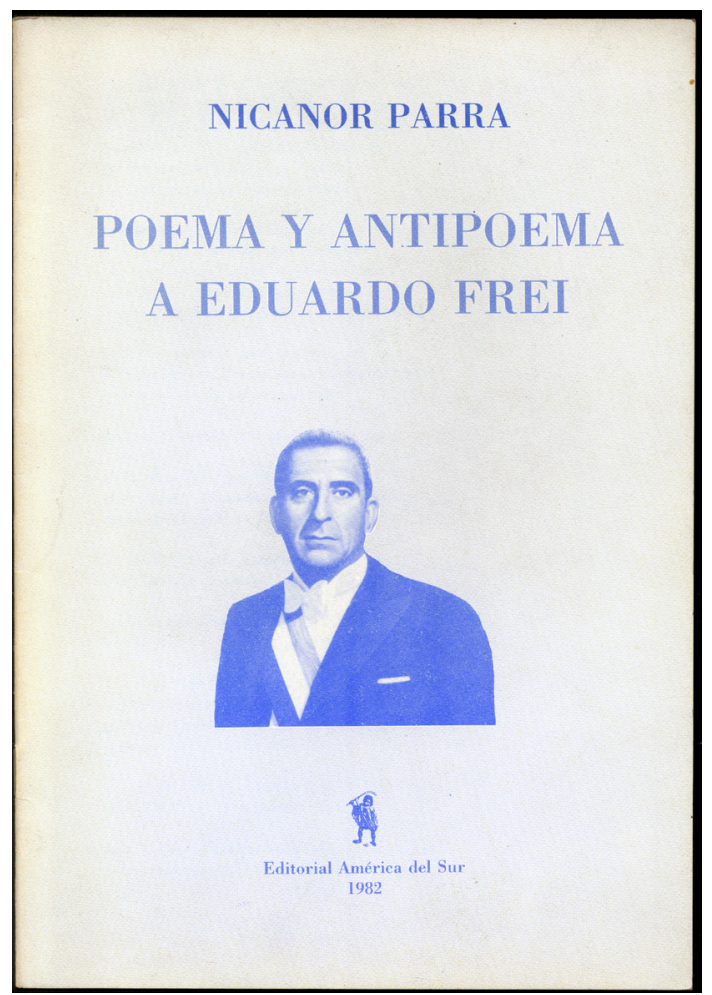

Poema y antipoema a Eduardo Frei, 1982.

HOJAS DE PARRA. Número 1. Valparaíso: Gráfica Marginal, otoño 1982.

Reproducción holográfica, de 36 por 26 centímetros, del manuscrito del poema "Amor no correspondido".

CHISTES PARAA DESORIENTAR A LA POEHÁA POESÍA. Segunda edición. Santiago de Chile: Galería Época y Universidad Federico Santa María, 1983.

Para esta edición se repitió la misma fórmula de los Artefactos de 1972. La directora de la Galería Época, Lily Lanz, convenció a Parra para que un importante grupo de artistas locales ilustraran estos nuevos "artefactos" salidos de su pluma, que habrían de imprimirse, como los de 1972, en forma de tarjetas postales (de 13 por 9 centímetros) en un total de 250 , empaquetadas sin orden en una caja de cartón. 
*

o CONTAHINACLON O CORUNISMO

Nashluigtou is (UPI)

los seuras recologas extán locos:

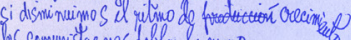

los comenustag nos doblan la manto

la delentistion ya se sabe cuáles:

o contamuiacion

- comunisino

no hay $x$ dople perlesse

eutre 2 males el menor

y.

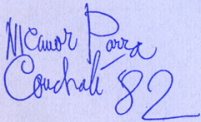

ECOPOEMIAS

DE

ITICANOR

PARRA

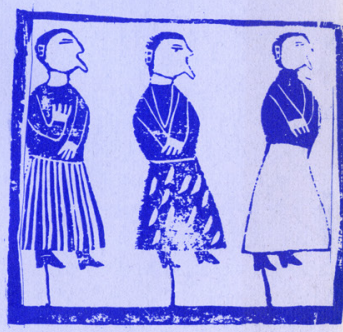

(pájaro de cuentas No 1)

\section{es SONÓ LA ANTIFOESÍA $\sum_{11}$ ta no es una fuarza creadora se qualó en lo que era la fortre \\ il la vebelléa x la rebeldía}

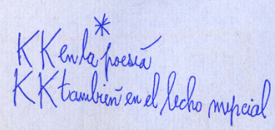
*

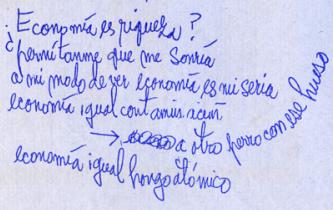

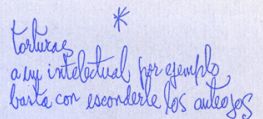

*

OSO PELLGRO A CERO METROS

*

ERPATAS II

dice enun comienzo fré é buabo debedear " " "núnero dice viva el Tachosanoza debe decir muera

dice $2+2 \operatorname{son} 4$ debedicir $2+2$ fueron 4 hoy nose sabe mada al respecto

Ecopoemas, 1982. Pliego de ocho páginas, con nueve poemas. 


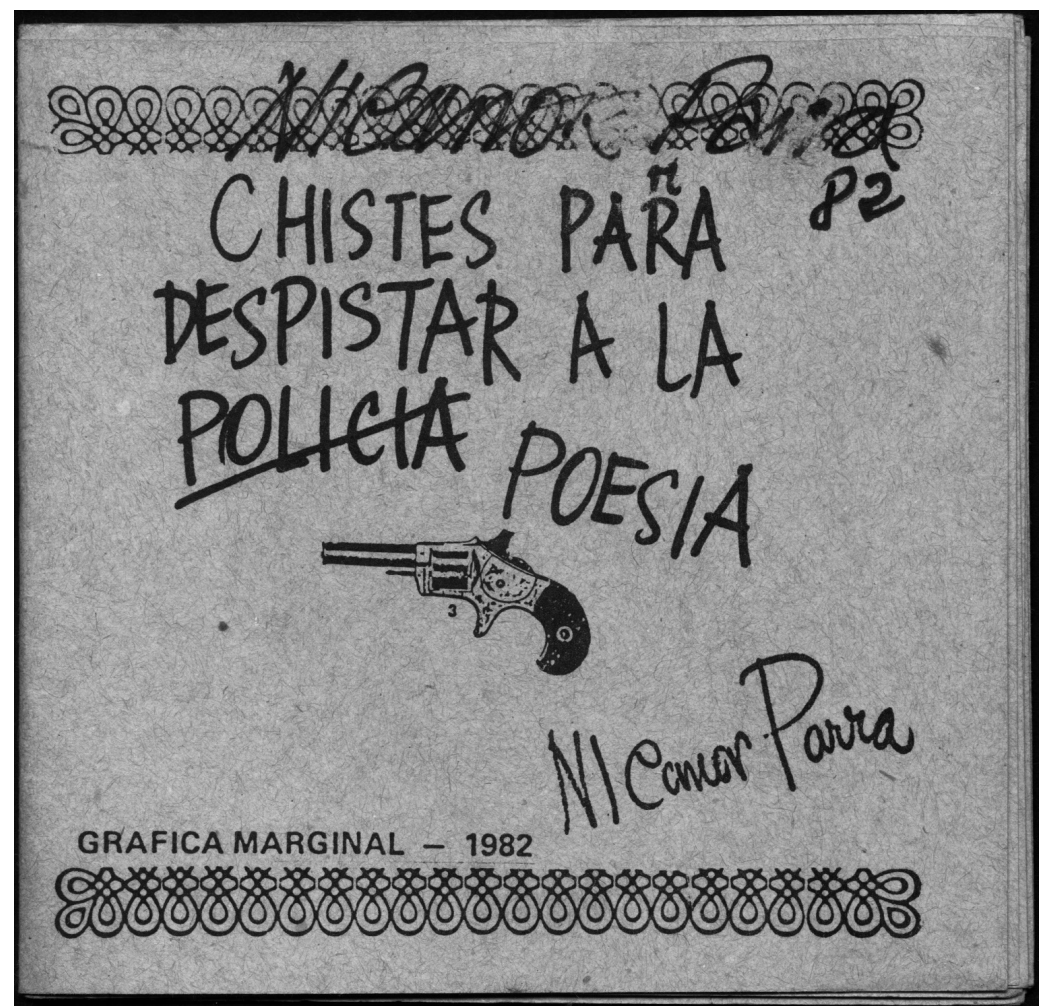

Primera edición de Chistes parfa despistar a la policia poesia, 1982.

Los artistas convocados fueron: Tatiana Álamos, Carmen Aldunate, Germán Arestizábal, Gracia Barrios, José Basso, Bororo, Marylin C. Bronfman, Roser Bru, Francisco Brugnoli, Marco Carreño, Gonzalo Cienfuegos, Gonzalo Díaz, Irene Domínguez, Luz Donoso, José Antonio Ferrer, Patricia Figueroa, Óscar Gacitúa, Gaspar Galaz, Eduardo Garreaud, Óscar Hahn, Gilda Hernández, Virginia Hunneus, José Ángel Cuevas, Patricia Israel, Alejandra Izquierdo, Helga Krebs, Enrique Lihn (quien además fue el presentador oficial), Mónica Lihn, Benjamín Lira, Luis Mandiola, Carlos Maturana, Gonzalo Meza, Manuel Torres, Pedro Millar, Humberto Nilo, Carlos Ortúzar, Inés Paulino, Francisco de la Puente, Chantal de Rementería, Patricia Saavedra, Francisca Sutil y Patricia Vargas. 


\section{HO JAS DE PARRA}

AMOR NO CORRESPONDIDO

(muainito)

Bajando de Machue Prcchu hater chale

perlas chalay du cuna chola

chigyas challoy

mas linde gue tuna vicuña

perlas ghallay

fero ella no me hito caso

halomilay!

Enes demasiado viefo

perlas challay.

me dyo y hivis reendo

chiguas chailay y Io me guedé peusendo qué cosas tiene fa vida

Hejor que me nuelowa Chule houlaschallay donde me ephera ni viefa

chievar chally. 0 Cor nuis 7 ratoncitos

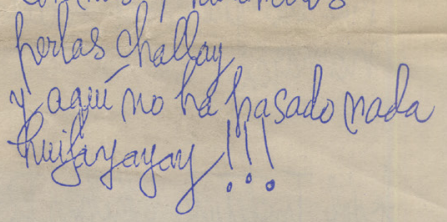

horlas challay

.

.
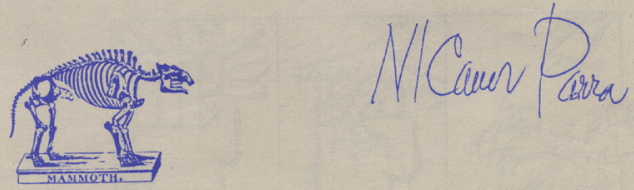

\section{número 1 otoño 1982}

Hojas de Parra n. ${ }^{1}$, 1982. Reproducción holográfica del manuscrito del poema "Amor no correspondido". 


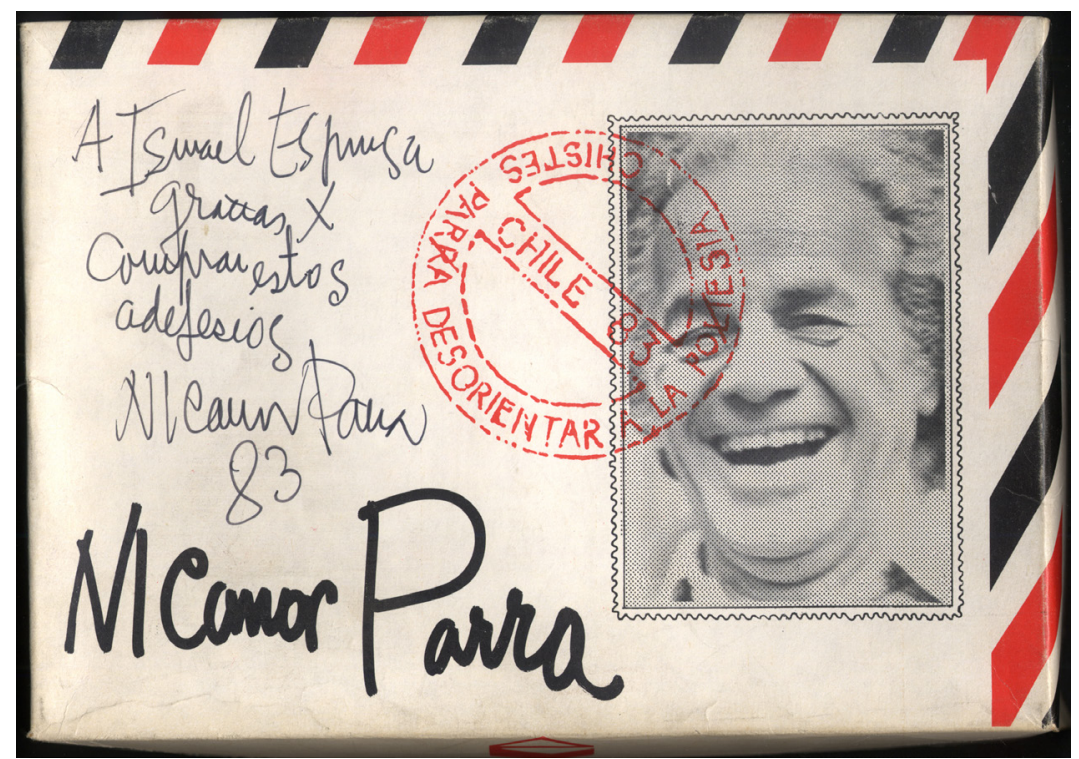

Segunda edición de Chistes parfa desorientar a la policia poesia, 1983.

No todos contribuyeron con igual número de postales. Algunas de éstas sólo reprodujeron el texto correspondiente en la caligrafía del propio Nicanor Parra. Tatiana Álamos confeccionó, para una edición de lujo, diez cajas de madera de álamo tallada, con dibujos alusivos a las postales realizados por ella misma. Estas diez cajas incluían un casete con la voz de Parra.

POESÍA POLÍTICA. Santiago de Chile: Bruguera, 1983.

Antología de la poesía de Nicanor Parra prologada por el novelista Enrique Lafourcade.

COPLAS DE NAVIDAD (ANTIVILLANCICO). Santiago de Chile: Talleres de Ediciones Minga, 1983.

En 1983, la editora de un diario de circulación nacional dio al poeta Hernán Miranda Casanova la tarea de encomendar a Nicanor Parra la escritura de unas coplas para ser publicadas en la edición de Navidad. Después de escritas y en vez de multiplicarse en doscientos mil ejemplares, como se había pensado originalmente, el diario rechazó su publi- 


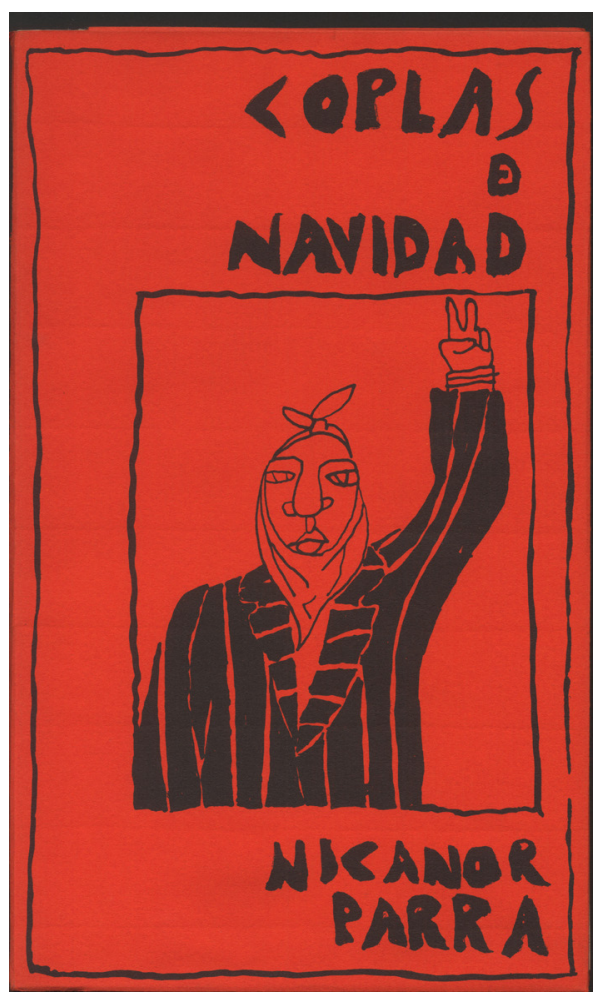

Coplas de Navidad, 1983, con ilustraciones y diseño de Óscar Gacitúa.

cación debido al contenido político de las Coplas de Navidad. En esas circunstancias, el artista plástico Óscar Gacitúa concibió la publicación artesanal de esta obra en mil ejemplares para ser repartidos entre amigos.

Las ilustraciones y el diseño gráfico fueron realizados por el pintor Óscar Gacitúa. La impresión se realizó mediante xilografía, en grandes hojas de color rosado y plegadas en cinco partes, cada una con tapas de cartón forradas en papel de color rojo. En la contratapa se puede leer: "Ediciones del Camaleón". Algunos de los ejemplares fueron firmados por el autor.

HOJAS DE PARRA. Santiago de Chile: Ediciones Ganymedes, 1985.

David Turkeltaud presenta esta obra con la siguiente nota:

La historia de los títulos de este libro forma parte, necesariamente, de este libro. El primer título retenido, allá por 1978, fue 


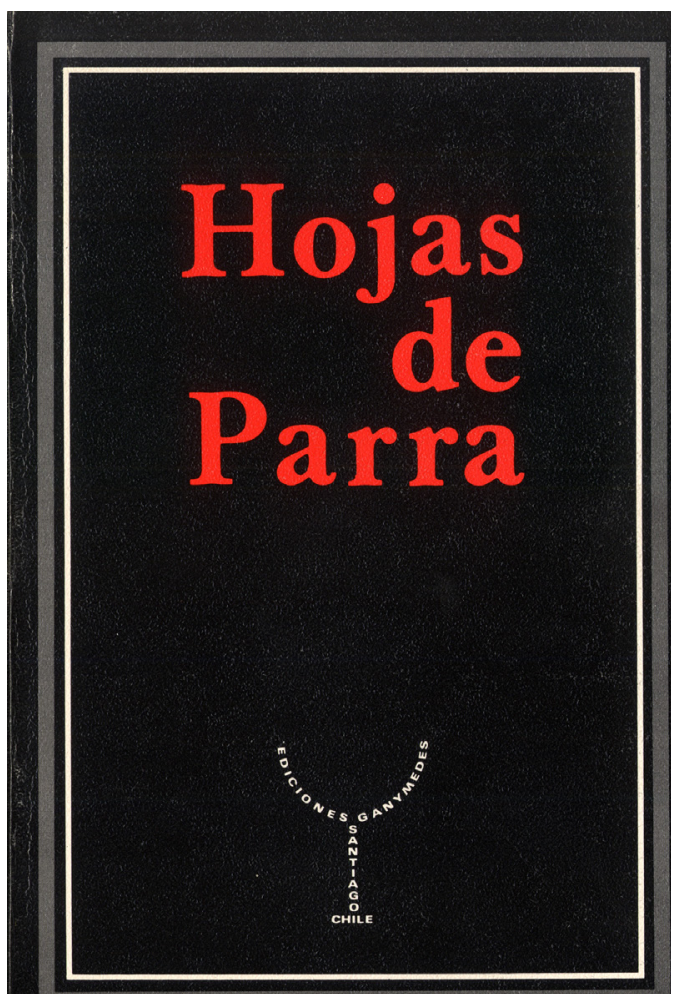

Primera edición de la antología Hojas de Parra, 1983.

"Cachureo"; el último, a comienzos de este año, "Ampliaciones". Entremedio "Coche de guagua", "Demoliciones y restauraciones", "Algo por el estilo" (título que utilizo aquí para una reunión de poemas breves). "Base de operaciones", "Ejercicios respiratorios" y "Cero problema" dan cuenta de los acercamientos y alejamientos del autor a esta parte de su obra, en que recoge, por primera vez desde 1969, sus poemas y antipoemas.

Hay que recordar que este título corresponde a una época de intensa búsqueda y experimentación: desde el estallido del (anti) poema en Artefactos (1972) y Chistes para desorientar a la poesía (1983), hasta la entrega total de la palabra a un hablante extraño: Sermones y prédicas del Cristo de Elqui (1977) y Nuevos sermones y prédicas del Cristo de Elqui (1979). Ninguno de estos experimentos fue gratuito en sí, y todos ellos aportaron elementos importantes a la maestría con que se desenvuelve Parra en estas Hojas. 
Entre "Cachureo" y "Ampliaciones" han pasado siete largos años y se han escrito muchas páginas: "Proyecto de tren instantáneo" (1978), "Mónica Silva" y "El hombre imaginario" (Conchalí, octubre-noviembre de 1979), "El poeta y la muerte" y "El antiLázaro" (1981), que se cuentan entre las mejores jamás salidas del bolígrafo del poeta.

Finalmente $-\mathrm{y}$ termino con la historia del título-, Hojas de Parra surgió como una solución de compromiso entre "Poemas dispersos" y "El hombre imaginario y otros poemas". Quedaron en el camino "La camisa de once varas", "Material de lectura", "Acto de presencia" y "La bicicleta del alcalde".

Los textos incluidos en la sección I fueron escritos entre 1969 y 1973 y publicados en diversas revistas y antologías. En las secciones II y III se han agrupado textos escritos desde 1975 hasta abril de este año y que se encontraban, en su mayor parte, inéditos.

Esta primera edición de Hojas de Parra se terminó de imprimir en el mes de junio de 1985 en los talleres de la imprenta Pucará, Matucana n. ${ }^{\circ} 1509$, Santiago de Chile. La edición fue de 2.000 ejemplares en papel hilado de 106 gramos y de 85 ejemplares impresos en papel gofrado de 130 gramos, numerados del 1 al 85 y firmados por el autor.

Hojas de Parra fue reeditado por Ediciones Cesoc, Santiago de Chile, en 1996, ocasión en que se hizo un volumen doble que podía abrirse por las dos caras, como si se tratara de dos libros, y que incluía en la parte inversa a Hojas de Parra, un álbum de Trabajos prácticos, con las reproducciones de los dieciséis trabajos expuestos en 1992 con Joan Brossa en España. De esta exposición existe catálogo ilustrado con biografías ilustradas: Joan Brossa / Nicanor Parra. dir poesía / mirar poesía, març-abril 1992, Sala d'Exposicions / Universitat de València, october-december 1992.

POEMAS PARA COMBATIR LA CALVICIE. México: Fondo de Cultura Económica, 1993.

Antología compilada y prologada por Julio Ortega. En esta edición, la tipografía y formación fue realizada por Yolanda Morales en el taller de composición electrónica del Fondo de Cultura Económica, y cuyo cuidado estuvo a cargo de Ricardo Rubio. La primera edición fue de 3.000 ejemplares. 


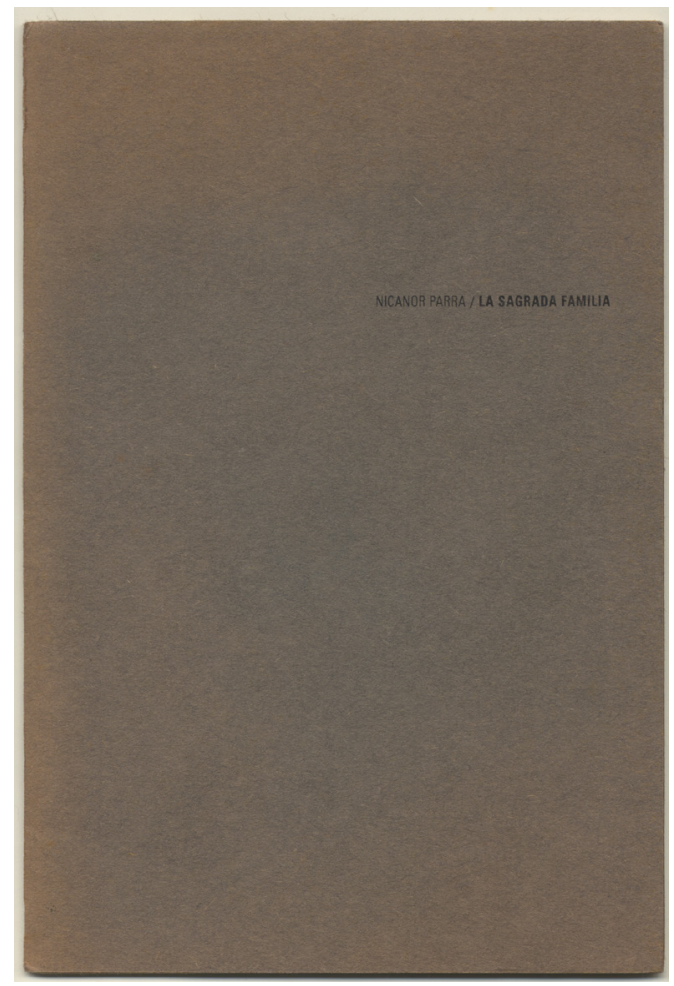

La Sagrada Familia (rap), 1997, de solo 38 ejemplares numerados.

LA SAGRADA FAMILIA (rap). Santiago de Chile: Ediciones La Sabrosa, 1997.

Edición privada de 38 ejemplares numerados, de los cuales 19 son para el autor y 19 para el editor, Juan Guillermo Tejeda. Confeccionada manualmente en Ediciones La Sabrosa, una edición del holding La Máquina del Arte.

PÁGINAS EN BLANCO. Salamanca: Ediciones Universidad de Salamanca y Patrimonio Nacional, 2001.

Antología del antipoeta, con una selección y edición al cuidado de Niall Binns, publicada en celebración del X Premio Reina Sofía de Poesía Iberoamericana. La introducción de María Ángeles Pérez López precisa el concepto de antipoesía y su contexto histórico en la poesía chilena. La selección se extiende desde Poemas y antipoemas hasta dis- 


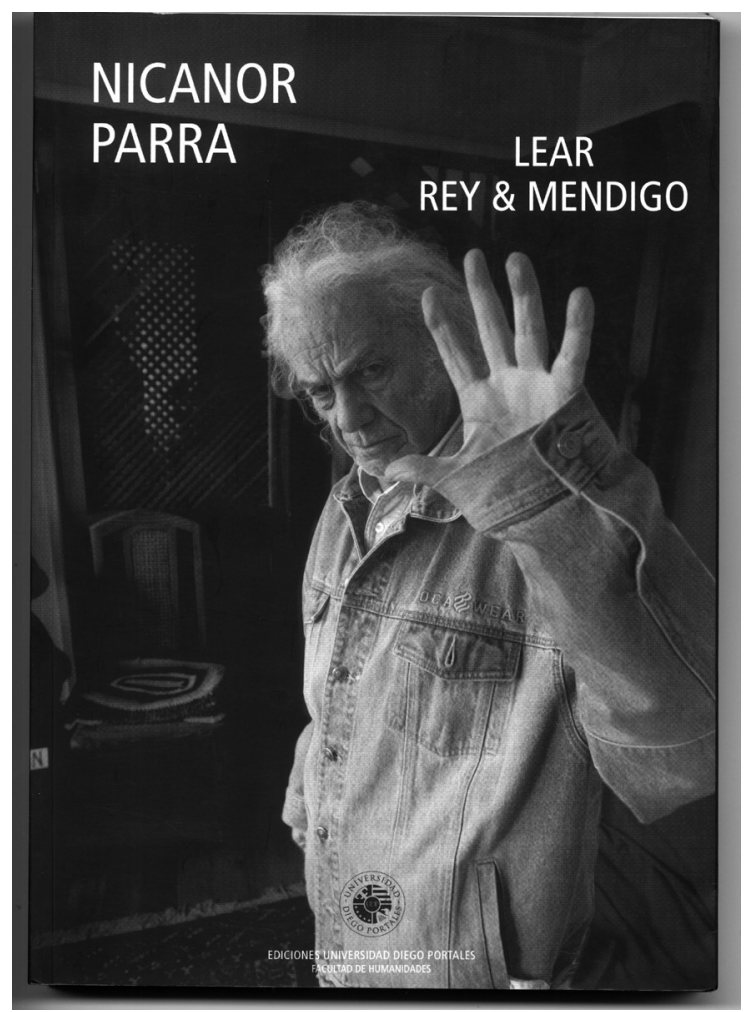

Lear. Rey \& mendigo, 2004.

cursos, artefactos visuales, inéditos y manuscritos que alcanzan hasta el año 2001, en la muestra más amplia y variada que se conoce de Nicanor Parra en España hasta ese momento.

LEAR. REY \& MENDIGO. Santiago de Chile: Ediciones Universidad Diego Portales, 2004.

Ésta es la traducción de la tragedia de Shakespeare que Nicanor Parra emprendió en 1990 a petición de Raúl Osorio, destinada al montaje de la obra por la Escuela de Teatro de la Universidad Católica. Bajo la dirección de Alfredo Castro, la obra fue estrenada en abril de 1992.

DISCURSOS DE SOBREMESA. Santiago de Chile: Ediciones Universidad Diego Portales, 2006.

Edición al cuidado Adán Méndez y Vicente Undurraga. Se trata de la primera versión "autorizada" de unos textos escritos entre 1991 y 
1997, en su mayor parte aparecidos previamente en antologías, revistas y páginas web, de forma individual y en versiones no revisadas por el autor. Los textos contenidos son:

—"Mai Mai Peñi (Discurso de Guadalajara)": Fue leído el 23 de noviembre de 1991, en la inauguración de la V Feria Internacional del Libro de Guadalajara, con ocasión de la recepción del primer Premio Internacional de Literatura Latinoamericana y del Caribe, Juan Rulfo, otorgado por la Universidad de Guadalajara.

- "Happy Birthday (Discurso del Caupolicán)": Pronunciado el 23 de abril de 1993 en el Teatro Caupolicán, Santiago de Chile, con ocasión del Congreso del Teatro de las Naciones.

- "Also sprach Altazor (Discurso de Cartagena)": Discurso leído por primera vez el 3 septiembre de 1993, en el poblado de Lo Abarca, cercano a Cartagena (Chile), con motivo de la celebración del centenario del nacimiento de Vicente Huidobro. El mismo discurso fue también pronunciado en la XXI Feria Internacional del Libro de Buenos Aires, Argentina, en abril de 1995.

-Discurso del Bío Bío: Pronunciado en la Universidad de Concepción en enero de 1996, con motivo de la recepción del doctorado Honoris Causa por esa casa de estudios.

-Aunque no vengo preparrado. Pronunciado en diciembre de 1997 en Valdivia, con motivo de la recepción del Premio Luis Oyarzún, otorgado por la Universidad Austral de Chile.

-Talca, París \& Londres. Un discurso que está por escribirse. Discurso leído en la ceremonia de imposición de la Medalla al Mérito Juan Ignacio Molina, que le fue concedida en 1998 por la Universidad de Talca.

- Gracias muchas. El discurso que está por escribirse. Leído el 22 de abril de 1999, en la ceremonia de inauguración del año académico de la Universidad de Chile, ocasión en la que Parra fue condecorado con la Medalla Rectoral.

-No me explico señor rector. Discurso pronunciado en el Salón de Honor de la Universidad de Chile, el 28 de mayo de 2001, con ocasión de la entrega del Premio Bicentenario.

Hubo una primera edición parcial de esta obra, publicada en la serie Literatura de los Cuadernos Atenea, de la Universidad de Concepción, en mayo de 1997, pero no llegó a circular debido al veto que, una vez 


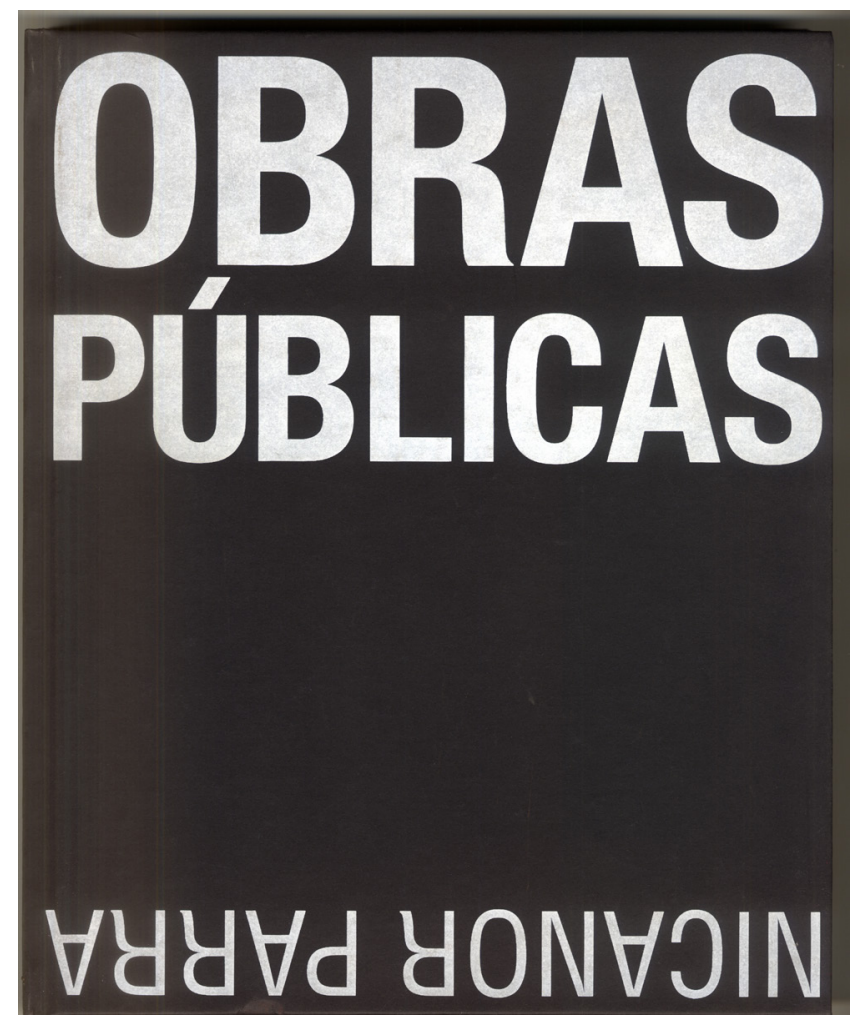

Obras públicas, catálogo de la exposición realizada en 2006.

impresa, le impuso Nicanor Parra, por los errores de toda naturaleza que se podían apreciar al abrir el libro. Hemos podido ver un ejemplar con la siguiente escritura en la página 75: "Impresión desautorizada por el autor; está plagada de gazapos, errores y horrores de imprenta \& What not...iiii fue transcrito de una grabación!!!! Firmado: Nicanor Parra 2000.

OBRAS PÚBLICAS. Santiago de Chile: W.R.S. Producciones, 2006.

Este libro fue presentado como un catálogo de la exposición “Obras públicas”, realizada el año 2006 en el Centro Cultural Palacio de La Moneda, en el cual el arte visual de Parra se transformó en monumentales instalaciones, como "El pago de Chile", donde aparecen los Presidentes de la República de Chile ahorcados y colgados del techo.

En el diseño gráfico, asesoría editorial, producción ejecutiva y fotografías participaron Colombina Parra, Patricio Fernández, Hernán 


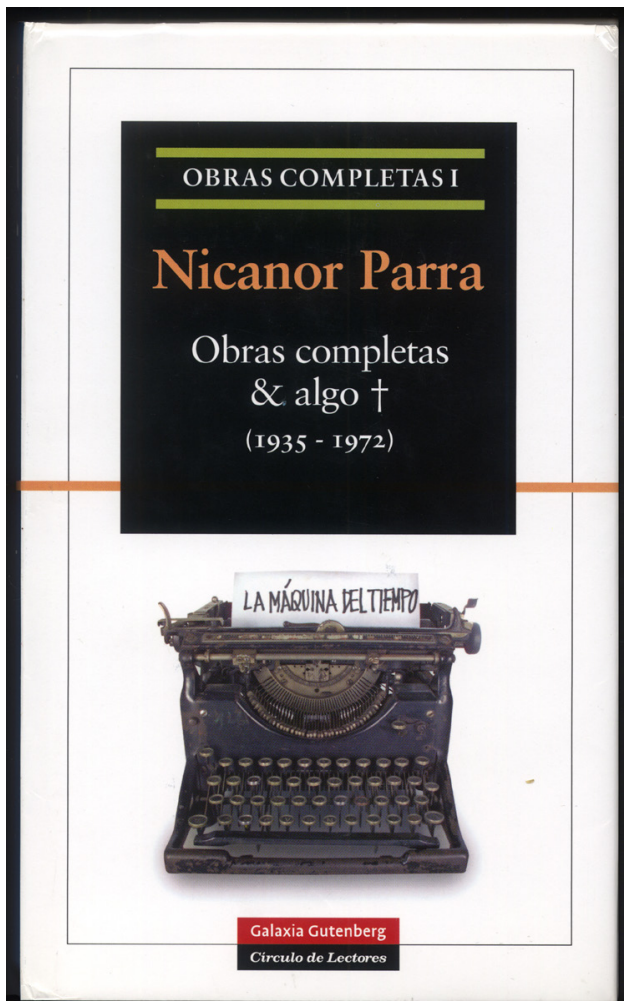

Primer tomo de Obras completas \& algo + (1935-1972).

Edwards y Rodrigo Avilés. En la diagramación, dirección de arte, maquetas y corrección de textos: Pablo Fernández, Ximena Cubillos, Juan Sebastián Espejo y Humberto Ahumada. Edición de 2.500 ejemplares.

OBRAS COMPLETAS \& ALGO + / Vol. I (1935-1972) / Vol. II (19752006). Barcelona: Galaxia Gutenberg - Círculo de Lectores, 2006; y Galaxia Gutenberg - Círculo de Lectores, 2011.

La edición del primer volumen estuvo al cuidado de Ignacio Echevarría, el diseño fue de Winfred Bährle, según una idea original de Norbert Denkel. La producción fue de Susanne Werthwein. La fotografía del estuche: Nicanor y Roberto Parra (colección particular). Fotografía de la sobrecubierta: "La máquina del tiempo", artefacto visual de Nicanor Parra fotografiado por Roberto Edwards. 
La edición del segundo volumen fue establecida y anotada por Niall Binns e Ignacio Echevarría, con la colaboración del poeta Adán Méndez. La fotografía de la cubierta es de Hernán Edwards y Colombina Parra: "El paso del tiempo".

TEMPORAL. Santiago de Chile: Ediciones Universidad Diego Portales, 2014.

Obra escrita en enero de 1987 y extraviada durante más de 20 años, Temporal aparecía una y otra vez en las conversaciones de Nicanor Parra. Redescubierto a partir de las grabaciones hechas por René de Costa en Chicago durante sus conversaciones con Nicanor Parra. EP 